\title{
Aproximación histórica a la reformulación lingüística de la paráfrasis como un caso de sinonimia sintagmática ${ }^{1}$
}

\begin{abstract}
Resumen
En el presente artículo se estudia la reformulación parafrástica, sus diferentes tipos y su evolución en español. La investigación es teórico-práctica puesto que se ofrece un estudio teórico de la paráfrasis desde distintas disciplinas y una aplicación práctica mediante el análisis de ejemplos extraídos de tres conocidos corpus: CREA, CORDE y DAVIES. Consideramos que no se ha desarrollado aún una satisfactoria teoría lingüística sobre la reformulación parafrástica en el marco semiótico de un estudio sintáctico-semántico y pragmático, integrador e interdisciplinar, por lo que esta investigación aspira a aportar, por medio del análisis del corpus de ejemplos seleccionado, algún dato que resulte revelador al conjunto de los estudios sobre el fenómeno de la paráfrasis.
\end{abstract}

\section{Palabras clave}

semiótica, semántica, sinonimia sintagmática, reformulación lingüística, paráfrasis, equivalencia, explicación.

\begin{abstract}
In the present work we study the paraphrastic reformulation, its different kinds and its evolution in Spanish language. The research is theorical and practical, because we offer a theoretical study of paraphrase from diverse doctrines and a practical application to analysis of examples taken from three known corpus: CREA, CORDE and DAVIES. We consider that there isn't yet a satisfactory linguistic
\end{abstract}

* La autora es profesora titular de Lengua española en la Universidad Autónoma de Madrid. Investigación y publicaciones acerca de temas de Semántica, léxico, morfología, traducción, análisis del discurso y ciberlenguaje. Enseña semántica del español, léxico del español, fonética y fonología del español, gramática del texto.

Libros: El lenguaje dramático de Lope de Vega (Cáceres, Universidad de Extremadura, 1996), Cambio semántico y competencia gramatical (Madrid/Frankfurt am Main, Iberoamericana/Vervuert, 2009), Estudios sobre el texto. Nuevos enfoques y propuestas (en coedición con R. González. Frankfurt am Main, Peter Lang, 2009), Traducción e interculturalidad. Aspectos metodológicos teóricos y prácticos (en coedición con R. Martín. Rabat, Universidad Mohamed V de Rabat, Universidad de Bergen de Noruega y Editorial CantArabia, 2009). Es también autora de artículos sobre el español de España y el español de América, tanto en la época medieval, áurea como contemporánea. Actualmente está preparando la edición de dos libros: Investigaciones fónicas transversales (Editorial Ariel) y Teoría y práctica de la traducción (Editorial Síntesis)

Correo-e: azucena.penas@uam.es

** La autora es licenciada en Filología Hispánica por la Universidad Nacional de Educación a Distancia y en Periodismo por la Universidad Complutense de Madrid. Ha cursado los Posgrados de "Español como lengua extranjera: enseñanza y aprendizaje" en la Fundación UNED, así como el de "Máster en lengua española: investigación y prácticas profesionales" en la UAM. Actualmente está realizando la Tesis Doctoral en semántica del discurso, con el título "Estudio contrastivo del funcionamiento semántico de los encapsuladores nominales en la prensa española y alemana. De la anáfora a la catáfora conceptual”, dirigida por la Dra. Ma Azucena Penas Ibáñez, en la Universidad Autónoma de Madrid. Por oposición libre obtuvo una plaza de profesora de enseñanza secundaria, en la especialidad de Lengua castellana y Literatura, con destino actual en el Instituto de Enseñanza Secundaria "Marqués de Villena", de Marcilla (Navarra).

Correo-e: sil.abad@estudiante.uam.es

1 Esta investigación ha sido realizada en el marco del proyecto Lingüística de E. Coseriu y lingüística coseriana (ref. FFI2008-04605), subvencionado por el Ministerio de Ciencia e Innovación para el plazo de ejecución 01/01/2009-31/12/2011. 
theory about the paraphrastic reformulation according to syntactic-semantic and pragmatic integrative point of view. Therefore, this paper tries to find some revealing data for the paraphrase, through an interdisciplinar semiotic analysis of the selected examples.

\section{Keywords}

Semiotics, Semantics, syntagmatic synonymy, linguistic reformulation, paraphrase, equivalence, explanation.

El presente artículo es un estudio:

1) del fenómeno de la reformulación parafrástica como un mecanismo que la lengua pone a disposición del hablante para expresar una misma idea;

2) de los diferentes esquemas y modelos en los que aquella puede formularse;

3) de cómo estos modelos pueden presentarse a lo largo de la historia del español.

El análisis consiste en un trabajo teórico-práctico a partir de una serie de ejemplos tomados de diferentes corpora del español, diacrónicos y sincrónicos, (CORDE, CREA y DAVIES), con el fin de poder establecer una definición más concreta del fenómeno y una descripción sistemática de sus diferentes mecanismos de expresión y funcionamiento.

La paráfrasis ha sido objeto de estudio por parte de diferentes disciplinas y consecuentemente puede ser abordada desde diversos puntos de vista. Tradicionalmente se la ha considerado como una relación de equivalencia de contenidos, inscribiéndose dentro de la sinonimia en la semántica teórica. Nuestra hipótesis consiste en incluirla dentro de un tipo de sinonimia, la sinonimia sintagmática. Por ello, últimamente está recibiendo tratamientos diferentes desde la pragmática y el análisis del discurso, es decir, desde la semántica textual, como reformulación parafrástica. Sin embargo, no se ha desarrollado aún una satisfactoria teoría lingüística sobre la reformulación parafrástica en el marco semiótico de un estudio sintáctico-semántico y pragmático, integrador e interdisciplinar, por lo que esta investigación aspira a aportar, por medio del análisis del corpus de ejemplos seleccionado, algún dato que resulte revelador al conjunto de los estudios sobre el fenómeno de la paráfrasis.

En primer lugar se va a revisar brevemente el concepto, más amplio, de reformulación lingüística, como mecanismo en el que se inscribe la reformulación parafrástica. A continuación se realizará un repaso por los diferentes puntos de vista desde los que ha sido abordado y por las disciplinas implicadas en su estudio: Retórica, Gramática y Sintaxis, Lingüística Aplicada, Pragmática y Semántica. Una vez concluido el estudio de la paráfrasis desde los diferentes enfoques, se presentará una caracterización teórica de los distintos modelos y esquemas parafrásticos que se conocen con el fin de desarrollarlos y analizarlos después a partir de la aplicación a los ejemplos del corpus. Asimismo, por medio de este análisis podremos establecer otros posibles esquemas parafrásticos, su funcionamiento y su caracterización dentro del fenómeno de la reformulación parafrástica que hemos considerado como relación sintáctico-semántico-pragmática entre oraciones y enunciados. En el apartado dedicado a la conclusión, se valorarán los resultados del análisis realizado a partir del corpus y si los modelos parafrásticos propuestos tienen validez dentro del concepto de reformulación parafrástica que se ha establecido como hipótesis o si se puede aportar algún dato a la definición con el fin de corroborarla o modificarla. 


\section{El mecanismo de la reformulación lingüística}

La paráfrasis en tanto que reformulación parafrástica se inscribe dentro de un mecanismo más amplio, de carácter discursivo, que se conoce como reformulación lingüística y se define como el procedimiento de organización textual por el que el hablante vuelve sobre un enunciado previo para expresarlo de otra manera, equivalente o distinta, facilitando así la interpretación del mensaje a su interlocutor. Las motivaciones de este proceso son diversas: explicar y/o aclarar lo dicho; recapitular mediante una nueva formulación abarcadora; hacer una reconsideración y expresarla desde un nuevo punto de vista; establecer una separación de distinto grado respecto del segmento anterior; o corregir lo dicho en un miembro discursivo precedente. Estos constituyen los principales mecanismos de reformulación lingüística entre los que se pueden distinguir dos tipos de relaciones: parafrástica y no parafrástica. Si retomamos la definición de reformulación linguiística dada arriba, la consideración de equivalente o distinta es lo que fundamentalmente va a distinguir los dos tipos de reformulación, parafrástica y no parafrástica, respectivamente.

La reformulación no parafrástica se caracteriza por el cambio de perspectiva enunciativa entre la expresión de referencia y la expresión reformulada, con el consecuente distanciamiento que ese cambio conlleva. Según la relación existente entre el segmento de referencia y el segmento reformulado, se puede hablar de tres esquemas de reformulación no parafrástica: a) recapitulación, si los distintos segmentos que componen el miembro de referencia son recogidos sumariamente en un único miembro, que es el introducido por el marcador de reformulación; b) rectificación o corrección, si el segmento de referencia es presentado explícitamente como una formulación incorrecta a la que el segmento reformulado corrige o mejora, invalidándola; y c) distanciamiento, cuando el segmento reformulado se presenta como no relevante al miembro de referencia, reconsiderándolo desde otro punto de vista, con otro interés comunicativo. La presencia de los marcadores reformuladores es en estos casos obligatoria, ya que serán los elementos que expliciten la relación de reformulación que existe entre los miembros discursivos. Si se suprime el marcador, el enunciado será entendido como un miembro más de la cadena discursiva. Por otra parte, el marcador reformulador permite una reinterpretación del segmento que se reformula, según una nueva perspectiva enunciativa que se configura en virtud de las instrucciones semántico-pragmáticas del marcador reformulador utilizado. En cambio, la reformulación parafrástica ${ }^{2}$ se define

$2 \quad$ M P. Garcés (2008) afirma que la reformulación lingüística constituye "un proceso de reinterpretación discursiva que permite al hablante volver sobre su discurso previo para formularlo de una manera más ajustada en relación con sus intereses comunicativos y al interlocutor comprender adecuadamente lo que se ha pretendido comunicar". En nuestra opinión, el proceso de reinterpretación no es común a todos los modelos de reformulación lingüística, ya que en algunos casos puede no darse una reinterpretación, como ocurre en: a) en la traducción interlingüística vertical, por ejemplo del griego al castellano: "oftalmología: tratado de los ojos"; "flebitis: inflamación de las venas", donde únicamente se realiza una traducción directa

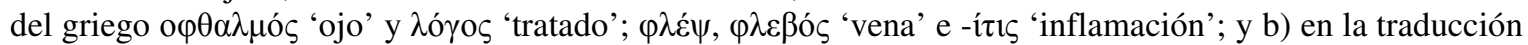
interlingüística horizontal, por ejemplo, del alemán al castellano: "Venenentzündung: inflamación de las venas”, donde solo se cambia un significante por otro, de código a código: al. Venen, cast. 'venas' y al. Entzündung, cast. 'inflamación'. Se trata en ambos casos -a) y b)-, de traducción metalinguíistica, donde se da una equivalencia totalmente denotativa o referencial, en la que no hay ningún plus de significado, es decir, donde la paráfrasis o traducción no conlleva ningún enriquecimiento sémico. Según la terminología de R. Trujillo (1996), se trata de "expresiones de situación", cuyo contenido no es un significado en sentido lingüístico, sino el nombre inconfundible con que identificamos un determinado referente; la paráfrasis, en estos casos, es nula, ya que no opera por explicación, sino por simple equivalencia denotativa. En la traducción de la poesía, sin embargo, prima la reinterpretación en la paráfrasis. En el presente trabajo partimos de la idea de que en la reformulación parafrástica, como mecanismo de explicación, siempre hay reinterpretación, por mínima que sea. Así, en el ejemplo siguiente, que tomamos del corpus manejado aquí, 
como una relación de equivalencia discursiva, basada, bien en una equivalencia semántica establecida entre los miembros discursivos, que se puede mostrar de modo gradual, de un máximo a un mínimo, o bien en una relación de identidad determinada por los marcadores reformuladores, en el caso de que la equivalencia semántica sea débil o no exista. Partiendo, por tanto, de la base de una equivalencia discursiva, la relación entre los miembros puede: a) apoyarse más en un parentesco semántico, que permitirá realizar un análisis basado en las relaciones significativas de los dos enunciados, de manera explícita; b) consistir en una identidad que se establece en un determinado contexto discursivo entre enunciados que se presentan como si fueran equivalentes, siendo una relación que se apoya más en un proceso inferencial, en un análisis de los vínculos implícitos entre las expresiones, más que en los rasgos propiamente significativos, y en la que la presencia de los marcadores reformuladores es necesaria para indicar la relación de equivalencia; y c) estar basada en la identidad del referente, tratándose entonces de una equivalencia designativo-referencial, en la que los miembros discursivos designan de manera inequívoca un objeto o una situación determinados en cuanto al referente, en cuanto que su contenido es producto de una convención acerca de la realidad.

Para explicar en qué consiste el concepto de equivalencia presente en las relaciones de reformulación parafrástica, hay que partir de la consideración tradicional de la paráfrasis como una relación de sinonimia, que implica, por tanto, la condición de la intercambiabilidad de la oración en todos los contextos, sin que se produzca ningún cambio en el valor, tanto cognitivo como emotivo, de la oración. Esta premisa, al igual que ocurre en la sinonimia, resulta muy problemática, puesto que la sustitución de una frase A por otra frase B supuestamente equivalente (en el sentido de sinónima) no funciona en todos los contextos. Así se comprueba en el siguiente ejemplo:

(1) A Juan, que admira la generosidad de las personas, le ha gustado el hecho de que...

(1A) María le haya prestado su bicicleta a Ana

(1B) *Ana le haya pedido prestada la bicicleta a María

donde se observa que estas oraciones, A y B, descontextualizadas, son equivalentes; pero en su contexto no se pueden considerar como tales y por lo tanto no se pueden intercambiar. Se comprueba, entonces, que las referencias extralingüísticas tienen un papel ineludible en la actualización de una oración, y que el concepto tan restringido de sinonimia no sirve para definir la relación semántica que se establece entre dos oraciones que se actualizan en una situación discursiva. La paráfrasis, definida dentro de un marco lógico, en términos de equivalencia semántica entre frases u oraciones (y no de equivalencia pragmática entre enunciados), minimiza la dimensión discursiva de la reformulación que la aproxima a un caso de sinonimia sintagmática. Excluyendo, por lo tanto, el concepto de identidad, ante la imposibilidad de utilizar el concepto de sinonimia para describir la relación parafrástica, la equivalencia se define como la relación que atribuye a los enunciados vinculados en la paráfrasis una base sémica común y una serie de rasgos diferenciales condicionados por la

donde puede parecer que no hay reinterpretación, el sintagma por andar introduce una reformulación donde hay algo de connotación, un plus semántico con respecto a la expresión antes: este implica una noción exclusivamente temporal, mientras que por andar es un concepto originalmente espacial, pero que en sentido figurado implica un significado temporal-espacial. Se trata de una metáfora lexicalizada para expresar una noción temporal:

(1) "Dada en Gaget. viij dias antes de las Kalendas de abril. Esto es; ocho días por andar del mes de março". (Estoria de España, s. XIII, DAVIES). 
situación y el contexto sintagmático. Este concepto de equivalencia semántica permite describir el parentesco semántico entre variantes parafrásticas, sin olvidar los contrastes semánticos que existen entre ellas. En otras palabras, marca la existencia de una invariante o nudo semántico común a una familia parafrástica, más allá de las inevitables diferencias que puedan presentar ${ }^{3}$. El interés que despierta el mecanismo de la reformulación parafrástica, sin embargo, consiste no ya en identificar una base sémica común o una equivalencia semántica entre los miembros discursivos que se ponen en relación, sino sobre todo en descubrir en qué condiciones interpretativas estos se pueden considerar equivalentes y cuáles son los mecanismos por los que se establece la equivalencia. El parentesco semántico y el contexto son, por tanto, los dos componentes esenciales a toda relación parafrástica entre enunciados, que podrían corresponder, respectivamente, a las dos formas de interpretación "heterogéneas y complementarias" a las que se refiere M. Prandi (1995): una, interna a la construcción del significado, que se configura como la intervención contextual de un sujeto en la puesta a punto de las articulaciones internas de un contenido complejo; y la otra, externa a la construcción del significado, que se presenta como un desarrollo inferencial realizado por un sujeto a partir del contenido de un acto de enunciación para aproximarse a su valor ocasional de mensaje.

Siguiendo a M. Prandi, es interesante destacar las dos acepciones de significado que según este autor intervienen en la relación de las estructuras semánticas e interpretaciones discursivas de los enunciados: 1) la estructural: entendiendo el significado como propiedad inmanente de las expresiones lingüísticas; es decir, concepto o significar; 2) la funcional: entendiendo el significado como mensaje que transmite un locutor en el momento de un acto de comunicación ocasional; es decir, intención o querer decir. Para los interlocutores del intercambio comunicativo, la configuración formal y la descodificación del contenido lingüístico de un enunciado están irreversiblemente orientadas hacia la interpretación de un mensaje, produciéndose así la "ilusión necesaria" de una transparencia del dispositivo estructural de la lengua: el significado de las expresiones parece adherirse perfectamente al valor del mensaje que adquiere en el acto de habla. A este concepto de la ilusión necesaria de la transparencia del lenguaje hace referencia también C. Fuchs (1982), cuando afirma que el paso del sentimiento de una continuidad funcional entre significados y mensajes a su identificación se trasluce en la actitud de los locutores en el momento de la evaluación de los actos de paráfrasis espontánea: expresiones intercambiables en términos de valor de mensaje son tratadas como otros tantos sinónimos. La identificación operada espontáneamente por los sujetos, según esta autora, tiene esta propiedad particular de tratar los semantismos retenidos como semantismos lingüísticos.

En virtud de los dos componentes fundamentales de la reformulación parafrástica -parentesco semántico y contexto-, los factores contextuales tendrán un mayor peso cuando la equivalencia semántica sea menor, y el parentesco semántico será más fuerte en los casos en los que el contexto tenga un peso más débil. Esta afirmación nos lleva a considerar la paráfrasis, en tanto que reformulación discursiva, como una relación semántico-pragmática, es decir, como una relación semántica relacionada con otros parámetros externos que presenta la lengua en uso y que la vinculan a la pragmática. De hecho, como afirma R. Rath (1975), la problemática de la descripción de la estructura de la paráfrasis reside esencialmente en la determinación de las paráfrasis como "textos especiales" en cuanto que se trata de textos expresados en situaciones concretas y bajo condiciones determinadas del hablante y del

3 Este concepto de equivalencia semántica lo desarrolla Mª A. Penas en (2009a). 
oyente. Por otra parte, la reformulación parafrástica como actividad discursiva tiene un interés especial dentro de la Pragmática, en cuanto que su funcionamiento se encuentra íntimamente relacionado con los estudios sobre los marcadores del discurso ${ }^{4}$ y los mecanismos de cohesión textual ${ }^{5}$.

\section{La reformulación parafrástica y la Retórica}

En la Antigüedad clásica, los estudios pre-lingüistas consideran la paráfrasis como el resultado de la actividad de un sujeto en una situación discursiva determinada, que realiza la reformulación de un texto original. Este concepto de paráfrasis es precisamente el que más tarde recogerán las teorías pragmáticas. Además de la aplicación de la paráfrasis a la exégesis o interpretación de determinadas obras, con el objetivo de producir un nuevo texto a partir de un original, al que explica o aclara con una función principalmente pedagógica e ideológica (paráfrasis explicativa), la Retórica considera la paráfrasis como un instrumento para la preparación del rétor, como parte de la maestría de la lengua, mediante el cual el orador demostraba, no solo conocer las expresiones más apropiadas para cada contexto, sino también estar en posesión de buenas aptitudes cognitivas. Este concepto de paráfrasis ha recibido el nombre de paráfrasis imitativa, pues se trata esencialmente de un mecanismo de sustitución, una suerte de plurivocidad ${ }^{6}$ que, también en la Retórica antigua, se aplicó al concepto de sinonimia como figura retórica que se da cuando una cosa (o un estado de cosas) se expresa con muchos nombres que indican lo mismo ${ }^{7}$. Es decir, cuando términos con sentidos diversos se refieren a las mismas cosas. Actualmente, el campo designativo (las cosas) ha quedado fuera de la sinonimia. Obsérvese que en la Antigüedad se hablaba de cosas, y no de significantes y significados. En la Retórica se explotó la capacidad de los sinónimos para combinarse y reemplazarse, fomentando la acumulación, la intensificación y la variedad expresivas. Y lo mismo se aplicó a la paráfrasis considerada como reformulación imitativa, que utiliza la acumulación de frases que denotan lo mismo en aras de la amplificación. En el siguiente párrafo de Quintiliano (De Institutione oratoria, I, §168), se comprueba la función expresiva de la paráfrasis:

A veces... los comienzos incluso y las cláusulas de las frases se corresponden entre sí usando palabras distintas, pero sin sentido distinto. Los comienzos de este modo: he arrastrado toda clase de peligros, me he expuesto a asechanzas, he afrontado el odio popular. E inmediatamente después las cláusulas: pues vosotros habéis tomado la resolución, habéis dado vuestro dictamen, habéis manifestado vuestro juicio. Esto lo llaman, unos, sinonimia, otros, disyunción. También se agrupan palabras que denotan lo mismo: ... se ha ido, se ha marchado, ha salido, ha escapado.

4 Para el estudio de la relación entre los diferentes tipos de reformulación parafrástica y los marcadores reformuladores, véase R. Rath (1975); Ma A. Martín Zorraquino y J. Portolés (1999); y J. Portolés (2001).

5 Para el estudio de la reformulación parafrástica como un elemento que contribuye a la estructuración y cohesión textual, véase R. Rath (1975); y Mª A. Penas (2009b).

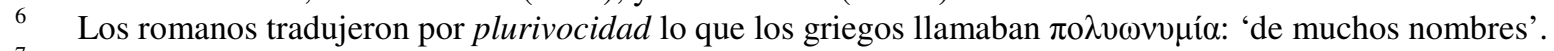

7 B. García-Hernández (1997a) habla de la sinonimia como figura retórica. La sinonimia en la Retórica antigua fue entendida como una plurivocidad (una cosa que se expresa con muchos nombres) basada no en la identidad significativa, sino ante todo en la equivalencia designativa, es decir, en la referencia común de los términos sinónimos. En definitiva, hay sinonimia cuando en un contexto de oraciones articuladas se expresa la misma idea con diferentes palabras. García-Hernández cita el siguiente ejemplo de Cicerón: "Nada realizas, nada emprendes, nada maquinas". 
Aristóteles trata en el Libro III de su Retórica ${ }^{8}$ de las diferentes maneras de expresar una misma realidad dependiendo de la situación del discurso, lo que en definitiva es la paráfrasis pragmática. Los factores o principios retóricos que influyen en la elección son: a) la posición del emisor según el contenido y la imagen de sí mismo que desea proyectar; b) la posición del receptor y los sentimientos que se quieren desarrollar en él; y c) el tema del discurso. Asimismo, los procesos estilísticos de la paráfrasis que cita el filósofo son, entre otros:

- la alternancia y repetición de sinónimos: ir y marchar;

- el uso de la perífrasis en vez del nombre simple: figura plana cuyos puntos son todos equidistantes del centro, por círculo;

- el uso de la metáfora, en este ejemplo, eufemística: el que se procura o consigue algo, por el que roba;

- el uso de ejemplos y comparaciones: la inteligencia es como la tierra fértil, hay que cultivarla.

En estudios más recientes, como el de R. Rath (1975), que trata sobre la paráfrasis en el ámbito de la comunicación, a la que llama paráfrasis comunicativa, esta es considerada como uno de los medios fundamentales de la explicación y precisión retóricas. La paráfrasis es para este autor un proceso retórico en el que la explicación, el desarrollo y profundización del pensamiento, la precisión y el establecimiento de una comprensión definitiva del discurso constituyen sus principales objetivos. Rath pone especial atención en la necesidad del mecanismo de la paráfrasis en la comunicación cotidiana, tanto oral, como escrita. Dado que no podemos expresar de una vez, en un todo, un contexto de circunstancias, un determinado acontecimiento, acción o descripción, a menudo resultan necesarias muchas apreciaciones, es decir, es necesario expresar "lo mismo con otras palabras", pero traídas en función de los diferentes aspectos y puntos de vista que aportan al discurso, para facilitar la comprensión y el consenso del interlocutor. En definitiva, "con la paráfrasis se debe alcanzar más que una simple repetición del asunto". Si bien considerada por R. Rath como proceso retórico, no se trata aquí de la acumulación de frases que denotan lo mismo, que expresan la misma idea, para contribuir a la amplificación, la acumulación y la variedad expresivas, como en la retórica antigua, sino que se trata de expresar lo mismo con otras palabras, siendo estas no una repetición, sino algo más que un enriquecimiento expresivo: es decir, han de aportar un punto de vista diferente con la función de explicar, profundizar o precisar, y con la finalidad de la comprensión definitiva del texto.

\section{La reformulación parafrástica y la Gramática}

En los manuales de Gramática, se usa la paráfrasis con una función metalingüística, para explicar determinadas expresiones y fenómenos gramaticales. Así, por ejemplo, en la Gramática de la Lengua Española de E. Alarcos (1994: 81-82), se emplea una paráfrasis para explicar el funcionamiento del adjetivo antepuesto o epíteto en el sintagma la blanca nieve, que -citamos de Alarcos-, "no designa a ningún tipo de 'nieve' que se oponga a otro que no sea 'blanco', sino que simplemente se describe cómo es la 'nieve', como si dijésemos 'la nieve con su blancura”,. La expresión como si dijésemos indica que el segmento introducido

8 Edición de A. Bernabé (2007). Véase también Maa A. Penas (2008b).

9 Traducimos del original en alemán: “das Gleiche mit anderen Worten”; y más abajo: “con la paráfrasis se debe alcanzar más que una simple repetición del asunto", al. "dass mit der Paraphrase mehr erreicht werden soll, als nur eine Wiederholung des Redethemas". (R. Rath, 1975). 
es una reformulación parafrástica ("la nieve con su blancura") de la expresión anterior ("la blanca nieve"), que sirve para entender mejor el mecanismo significativo del epíteto.

Desde el punto de vista de la Sintaxis, el caso paradigmático de paráfrasis es el que se expresa en la relación entre las estructuras sintácticas activas y las pasivas correspondientes. Estos serían casos de paráfrasis entendida como pura sinonimia sintáctica en los que se da una equivalencia lógico-semántica entre frases u oraciones y en los que la relación parafrástica podría entenderse como una propiedad de las formulaciones lingüísticas. La dimensión discursiva, por lo tanto, queda excluida. Así, entre las siguientes oraciones:

\section{a) Los castores han construido las barreras \\ b) Las barreras han sido construidas por los castores}

Existe, en principio, una equivalencia semántica, es decir, podemos considerarlas semánticamente iguales (sinónimas), aunque a la hora de trasladarlas al ámbito discursivo, para comprobar su intercambiabilidad, se comprueba que la primera será más aceptable en un texto que tematice los castores, mientras que la oración b) lo será en un texto que tematice las barreras. Presentan, por tanto, perspectivas comunicativas diferentes.

Otro caso ${ }^{10}$ de relación parafrástica en el nivel de la sintaxis se puede observar entre las tres oraciones siguientes:

a) Este establecimiento vende panes (activa)

b) En este establecimiento se venden panes (pasiva refleja)

c) En este establecimiento se vende panes (impersonal)

Para estudiosos de la sinonimia como R. Trujillo (1996), la relación de sinonimia que normalmente se concede entre una oración pasiva y su correspondiente pasiva refleja (como en el libro fue vendido y el libro se vendió) no pasa de ser una sinonimia "situacional" o referencial ${ }^{11}$. Por el contrario, en la teoría transformativo-generativa se habla de la sinonimia entre una oración activa y su correspondiente pasiva, porque tienen la misma estructura profunda, justificada por el hecho de que tienen el mismo sentido aunque presentan distinta forma superficial ${ }^{12}$. También se tilda de sinonimia la que se establece entre frases que tienen una misma correspondencia y se refieren a la misma realidad extralingüística ${ }^{13}$ :

10 Véase $M^{a}$ A. Penas (2008/2009a y 2008/2009b).

11 En cuanto a la traducción, R. Trujillo acepta como traducibles únicamente los textos técnicos, e incluso en estos ve ciertas dificultades importantes, como el que las definiciones se elaboran en cada lengua con el vocabulario de esa lengua, o la estructura sintáctica particular de cada lengua. Así, una oración reflexiva como a ocho mil metros se respira mal, introduce en español elementos de significado que no puede poseer su pretendido equivalente inglés, porque en esta lengua habría que traducir la impersonalidad del español con un people como sujeto "externo", mientras que la construcción española no hace alusión a los seres que respiran, sino al propio hecho de respirar, tomado en sí mismo. Trujillo no solo confirma la intraducibilidad interlingüística, sino que tampoco ve posible la traducción intralingüística (dentro de un mismo código lingüístico, la reformulación parafrástica). (R. Trujillo, 1996). Frente a esto, contrasta la opinión de José Saramago, recogida en un texto que envió el escritor al VIII Congreso de Escritores de España, en octubre de 2008, para quien "escribir" es "traducir", aunque sea en lengua propia. El escritor, según el poeta portugués, transporta y traduce lo que vive y siente, igual que lo hace el traductor; el trabajo de ambos consiste en pasar a otro idioma, en principio el suyo propio, aquello que en la obra original ya había sido traducido, es decir la percepción de una determinada realidad.

12 Á. López García (1977) afirma, sin embargo, que una oración activa y su correspondiente pasiva no pueden tener exactamente el mismo significado porque, en su opinión, la sinonimia absoluta no existe, de forma que dos expresiones distintas en cuanto al significante lo son también en cuanto al significado. Así, establece 
a) El Sr. Jones es profesor de Williams

b) Williams es alumno del Sr. Jones

Estas oraciones, como muy bien apunta J. Lyons (1979), no se considerarían sinónimas, sino únicamente equivalentes en cuanto al referente. La sinonimia, según este autor, como igualdad de significado, es una relación que se forma entre dos (o más) datos del vocabulario, por lo que es una cuestión que atañe al sentido, y no a la referencia. La identidad de referencia, para los datos que la tengan, es una condición necesaria, pero no suficiente, de la relación semántica de sinonimia.

En M. Fernández Lagunilla y A. Anula Rebollo (1995: 174-175; 277), encontramos otros ejemplos de relación parafrástica entre estructuras sintácticas:

a) entre una oración activa y su correspondiente pasiva: Vendió la ropa usada: La ropa usada fue vendida.

b) entre oraciones que contienen adverbios oracionales de diferentes clases y sus respectivas paráfrasis:

- Sinceramente, Juan se merecía el castigo (= soy sincero al decir que Juan se merecía el castigo)

- Probablemente hayan salido (= es un hecho probable que hayan salido)

- Juan archiva los expedientes cuidadosamente (= Juan es cuidadoso al archivar los expedientes)

Los adverbios recogidos en estas tres oraciones aportan matices semánticos distintos, que quedan claramente identificados y explícitos en las respectivas paráfrasis: en el caso de sinceramente, se expresa la actitud del hablante hacia el enunciado; probablemente incide en el contenido proposicional del mismo; y cuidadosamente tiene una función modal con un alcance oracional, aunque en ocasiones puede resultar ambiguo e incidir solo sobre el Sintagma Verbal.

Uno de los estudios conocidos de la paráfrasis en el marco de la gramática y la sintaxis es el de R. Nolan (1970: 39), quien propone formular un criterio adecuado para la descripción de la paráfrasis en la lengua inglesa. Según esta autora, la paráfrasis que normalmente se entiende como la reformulación, aclaratoria y explicativa, de una formulación anterior, no es susceptible de recibir una descripción o unos criterios de uso general, porque en gran medida es una relación que depende del hablante, del oyente y en general, de la situación discursiva. La paráfrasis que constituye su objeto de estudio es y citamos textualmente:

la relación, que parece ser reconocida por los hablantes, que una oración $a$ mantiene con una oración $b$ si y solo si $a$ significa lo mismo que $b$. Por lo tanto, si $a$ es una paráfrasis de $b$, entonces $b$ es una paráfrasis de $a$. Y si $a$ es una paráfrasis de $b$ y $b$ es una paráfrasis de una oración $c$, entonces $a$ es una paráfrasis de $c$. Y, estrictamente hablando, cada oración es una paráfrasis de sí misma.

Como se ve, le concede a la relación de paráfrasis dos atributos: por un lado, la reversibilidad; por otro, la transitividad. La transitividad es una propiedad, en principio, de la relación de

una diferencia clara de matiz, neutro y ponderativo, respectivamente, entre las oraciones Zaragoza fue conquistada por soldados de Roma y Soldados de Roma conquistaron Zaragoza.

13 Tomamos el ejemplo de B. García-Hernández (1997b). En sentido estrictamente semántico, el plano designativo referencial no afectaría a la sinonimia, ya que como fenómeno onomasiológico que es, compete al significado y a los significantes, no al referente. 
sinonimia, pero no de la paráfrasis entendida como reformulación parafrástica contextual o discursiva. La reversibilidad es una propiedad que puede presentar la reformulación parafrástica en algunos casos, según los contextos, pero que no funciona de manera sistemática dentro de la paráfrasis discursiva. Hay que advertir que R. Nolan considera la paráfrasis como una pura sinonimia, pero prefiere no adoptar este nombre, ya que la sinonimia se entiende tradicionalmente como la relación entre palabras o lexemas o entre secuencias de palabras menores que la oración. Aparte de esta razón, afirma la autora, no hay ningún otro motivo para no llamar al objeto de su estudio "relación de sinonimia oracional". Este concepto de paráfrasis (entendida como relación entre oraciones dentro de una lengua), es considerado por la autora como el equivalente de la traducción (entendida como relación entre oraciones de lenguas diferentes). Vamos a ver por medio de dos ejemplos, que tomamos de su libro, en qué consiste su concepto de paráfrasis:

1a) Whenever it rains, the ground gets wet

b) The ground gets wet everytime it rains

2a) This book is mine

c) This is my book

Por medio de la descripción estructural, formada por las categorías gramaticales o sus abreviaturas ( $\mathrm{S}$ - sentence; $\mathrm{V}$ - verbo; $\mathrm{N}$ - nombre, etc.), cada oración se convierte en una sentence form (Sf), a través de la sustitución de las palabras, morfemas y expresiones que la forman, por las categorías gramaticales correspondientes:

1a') Whenever $S_{1}, S_{2}$

b') $S_{2}$ everytime $S_{1}$

2a') This $N_{1}$ is mine

b') This is my $N_{1}$

Los dos criterios que propone esta autora para la identificación de la paráfrasis $\operatorname{son}^{14}$ :

1. $S f_{1}$ y $S f_{2}$ tienen la misma descripción estructural y cada par de oraciones que resulta de sustituir la descripción estructural por expresiones apropiadas, constituye un par de oraciones que son T-equivalent (equivalentes en términos de verdad o falsedad de las proposiciones).

2. $S f_{1}$ describe a $S_{1}$ y es una forma parafrástica de $S f_{2}$, que describe a $S_{2}$, y $S_{2}$ es idéntica a $S 1$ en la misma forma en que $S f_{2}$ es idéntica a $S f_{1}$.

Desde un enfoque estructural y transformacional, el lingüista americano Z. S. Harris (1981: cap. 12) considera la paráfrasis como una relación de equivalencia, que él llama transformación (y que representa mediante el símbolo $\leftrightarrow$ ), entre dos estructuras oracionales, formadas a partir de una particular sentence-form ${ }^{15}$, cuando la relación mantiene el orden de

14 Esta propuesta ha de considerarse una caracterización general de descripción de la paráfrasis, que se puede aplicar a las diferentes lenguas. Por otra parte, estos criterios son válidos también para la descripción del funcionamiento de la traducción. En su estudio, además, aplica estos criterios al inglés, y reformula la propuesta solo para esta lengua. (R. Nolan 1970).

15 Concepto similar al que emplea R. Nolan en el trabajo antes citado. Se trata de la estructura o esqueleto sintáctico de la oración, descrito por medio de las categorías gramaticales que sustituyen las palabras, morfemas y expresiones que forman la oración y que también se representa por medio de las abreviaturas correspondientes. 
aceptabilidad de las correspondientes oraciones que se pueden formar a partir de las dos sentence-forms. Por ejemplo ${ }^{16}$ :

- existe una transformación parafrástica entre $N V$ Aly y $N$ 's Ving is A, como en:

1) The ball rolls slowly and The ball's rolling is slow

(ambas aceptables, aunque la segunda es menos cómoda)

2) The rock rolls slowly and The rock's rolling is slow

(ambas igualmente aceptables)

- pero no existe transformación entre $N_{1} V N_{2}$ y $N_{2} V N_{1}$ :

3) A truck carried a boat and A boat carried a truck (las dos normales)

4) Man invented ether and Ether invented man

(la primera normal; la segunda sin sentido)

Z. S. Harris habla de un metalenguaje que está en la propia lengua, y que contiene dos tipos de transformaciones, que constituyen dos sistemas gramaticales: Report y Paraphrase. El primero se refiere al sistema por el cual una lengua se describe a sí misma. Toda lengua natural, según este lingüista, debe contener su propio metalenguaje, es decir, el conjunto de oraciones con las cuales hablar sobre cualquier componente de la lengua, incluyendo el conjunto de la gramática de dicha lengua. Además, cualquier descripción adecuada de la lengua tiene que mantener el metalenguaje como una parte de la lengua que no es inmediatamente distinguible. Este aspecto resalta el hecho de que una de las principales propiedades que definen las lenguas humanas es su capacidad para su propia descripción. En cuanto al sistema de la paráfrasis, Harris considera que la naturaleza de las restricciones gramaticales que gobiernan las regularidades e irregularidades de la lengua, puede ser descrita, especificada y explicada a través de paráfrasis redundantes. Y esto es posible en cuanto que estas redundancias disipan o por lo menos reducen significativamente las restricciones observadas en las expresiones de origen. Por ejemplo, a partir de la secuencia de origen:

5) He is richer than she (is)

se puede dar el siguiente equivalente:

5') The amount of his riches is more than the amount of her riches,

donde 5') es una versión gramatical relativamente libre de 5), y, simultáneamente, constituye también una descripción de los aspectos gramaticalizados de 5).

Lo mismo puede decirse de este otro ejemplo:

6) I travelled for five hours since I left Krakow, y su equivalente:

6') The occurrence of my travelling from the moment of my leaving of Krakow has a duration of five hours

Las paráfrasis redundantes de 5') y 6') corresponden al tipo de report mencionado por Harris como uno de los sistemas de la gramática de una lengua. El mecanismo del report permite

16 Todos los ejemplos están tomados de Z. S. Harris (1981). 
definir las restricciones gramaticales por medio de las redundancias explicativas (o paráfrasis). El report, en estos ejemplos, se vale del mecanismo de la paráfrasis.

Asimismo, en las siguientes oraciones:

7) *He is richer than she more than you are (rich)

7') The excess of (the amount of) his riches over hers exceeds (the amount of) your riches,

donde se puede formar el equivalente 7') a partir de la oración de 7) que, sin embargo, es imposible. A partir de 7') se comprueba la restricción de 7): la estructura comparativa se repite solamente entre pares y pares de miembros, como se observa en 7' '):

7'’) He is richer than she more than you are richer than me

La oración de 7') combina paráfrasis y report, es decir, se trata de un report cuyo funcionamiento se vale de la paráfrasis, mientras que la oración 7') consiste únicamente en una redundancia explicativa o paráfrasis.

En Z. S. Harris, la paráfrasis sufre una especialización sintáctica y se inscribe dentro de un marco más amplio, como es el report, sistema que establece una conexión con la anáfora conceptual y otra vinculación con los procesos metalingüísticos. Las conexiones con la anáfora conceptual se observan en las oraciones 5') y 6'), en la utilización de los sintagmas nominales amount y occurrence. Así se comprueba si se comparan con uno de los ejemplos de anáfora conceptual que tomamos de R. González Ruiz (2009) (el subrayado es nuestro):

(2) Un adolescente de 14 años fue detenido ayer acusado de participar junto a otros jóvenes en el incendio de una furgoneta de la Ertzaintza con un cóctel molotov en el paseo del muelle de San Sebastián. Los jóvenes rompieron un cristal del vehículo, lo rociaron con gasolina y lo prendieron fuego. En el momento de la agresión, los agentes se encontraban patrullando la zona. (ELPAÍ́S.com, 03/08/1995)

donde la agresión es el sintagma nominal "etiquetador" que recoge o "empaqueta" conceptualmente todo lo expresado en el enunciado anterior y que aparece subrayado.

\section{La reformulación parafrástica y la Lingüística Aplicada}

La reformulación lingüística presenta sus principales campos de aplicación en la enseñanza y aprendizaje de lenguas, así como en la traducción. En el primer caso, el proceso de la reformulación es una tarea básica para el aprendiz, que le ayudará a expresar lo que quiere comunicar y por la cual tendrá que desarrollar diferentes estrategias interpretativas para entender y hacerse entender en una determinada situación comunicativa. Dentro de un programa de enseñanza de segundas lenguas, la inclusión de la paráfrasis o de la reformulación lingüística en general, implica la consideración del nivel del léxico como uno de los objetivos específicos, así como el desarrollo de actividades que faciliten la comprensión, retención y utilización de unidades léxicas de diferente naturaleza. Por medio del mecanismo de la reformulación parafrástica, el aprendiz desarrollará todas las destrezas lingüísticas, en particular la interpretación y la comprensión de textos, sin olvidar la expresión e interacción orales. Por otra parte, el alumno puede establecer relaciones entre las unidades léxicas nuevas y las ya conocidas, de modo que desarrolle en gran medida su capacidad 
cognitiva e intelectual ${ }^{17}$. En general, utilizar una diversidad de paráfrasis enriquece la expresión oral y escrita cuando nos expresamos en una nueva lengua y resulta de gran ayuda a la hora de encontrar expresiones alternativas o adecuadas a un contexto concreto.

En el ámbito de la traducción, la reformulación parafrástica tiene una función ineludible: el traductor la emplea constantemente para trasladar su interpretación de un texto fuente, pretendiendo plasmar el verdadero significado del mismo. La competencia léxica del traductor en las dos lenguas, la de entrada y la de salida, resulta imprescindible para el correcto empleo de las paráfrasis, que utilizará principalmente para explicar o precisar determinados referentes del texto de origen, en el caso de que estos resulten difíciles de traducir o incluso sean intraducibles, lo cual sucede con frecuencia, a no ser que se trate de textos técnicos. Por otra parte, un buen dominio del nivel léxico aportará riqueza y variedad al texto que traduce y contribuirá a darle cohesión y coherencia, puesto que el traductor será capaz de establecer las correctas relaciones y redes correferenciales entre las distintas partes del texto y además podrá realizar una correcta conceptualización y abstracción de las diferentes unidades y fragmentos textuales ${ }^{18}$, lo cual redundará de manera positiva en la traducción. La paráfrasis se utiliza también para no repetir la misma expresión, aunque el referente textual esté claro, con la finalidad de enriquecer conceptual y expresivamente el texto. En este sentido, es muy importante que las reformulaciones que se van a realizar se refieran al mismo grupo conceptual y no a otro distinto, ya que podrían dar lugar a graves confusiones.

R. Trujillo (1996) trata los problemas de la traducción y la sinonimia en dos capítulos de su libro. Su posición es clara: de acuerdo con el principio de identidad ${ }^{19}$, en rigor, la traducción no existe. Como tampoco existe, según este principio, el sinónimo de un texto (o de una palabra), ni la explicación exhaustiva de un texto, que sería la paráfrasis. Los textos, según Trujillo, no son otra cosa que interpretaciones idiomáticas de sistemas de referentes, de modo que siempre habrá una distancia infinita entre todo texto y esos referentes que pretende representar. Según este punto de vista, la traducción es una operación tan quimérica como la paráfrasis; en realidad, constituirían únicamente actos de interpretación. Traducir consiste entonces en trasladar a una situación real lo que está escrito en una lengua y luego contar esa misma situación real en otra lengua, es decir, se trata de una doble traducción: primero, del texto a un hipotético referente (hipotético porque, según R. Trujillo, el traductor no traduce el significado del texto, como debería, sino que supone lo que ese texto dice o quiere decir);

17 Véase $\mathrm{M}^{\mathrm{a}}$ A. Penas (2008b), donde se ofrece un estudio de la reformulación lingüística y la aplicación práctica de este mecanismo en la enseñanza/aprendizaje del español como lengua extranjera. En él se destaca la necesidad de poner énfasis en el tratamiento del léxico como uno de los objetivos específicos de la programación de la enseñanza de segundas lenguas, puesto que el dominio de este nivel sirve para alcanzar otros objetivos, como es la adquisición de prácticamente todas las destrezas lingüísticas. En la actividad práctica propuesta en esta investigación, dedicada a la adquisición de las unidades léxicas que se refieren a la comida, se propone como uno de los objetivos el que el aprendiz pueda realizar paráfrasis en caso de necesidad como estrategia de comunicación.

18 La reformulación parafrástica (y la reformulación lingüística en general) se consideran también mecanismos de cohesión textual, relacionados con la anáfora conceptual, como veremos en el apartado dedicado a la paráfrasis en el marco de la pragmática.

19 El principio de identidad lo explica R. Trujillo (1996, Cap. XII y XIII), distinguiendo entre identidad y semejanza: la primera es algo ajeno a nosotros, es decir, es algo objetivo; la segunda alude a cosas que suceden en nuestro espíritu, es decir, es algo subjetivo. Según este principio, las cosas o entidades (así como los textos, a los que considera como entidades objetivas, ajenas al individuo) solo pueden ser iguales a sí mismas, de modo que solo guardarán unas con otras una relación de identidad, no de semejanza. La relación reflexiva es, por tanto, de semejanza; la relación no reflexiva, de identidad. Conforme a estos presupuestos, afirma este autor que ningún texto puede ser igual a otro. 
segundo, una nueva interpretación, en otra lengua, de ese primer referente. Este mecanismo de la doble traducción se puede aplicar a la reformulación parafrástica, que implicaría también un doble proceso: semasiológico, de interpretación de la formulación de referencia; y onomasiológico, de producción de la nueva formulación. Por otra parte, acepta Trujillo que los problemas de la traducción varían según se trate de textos técnicos o de otro tipo de textos menos referenciales, y dentro de estos últimos, hay diferencias entre aquellos que tienen una intención puramente referencial y aquellos que tienen un significado más abstracto ${ }^{20}$. La traducción de textos técnicos no implica interpretación, sino que únicamente consiste en la sustitución -en el sentido coseriano del término- de significante por significante. Esto mismo se aplica a la hora de establecer la equivalencia semántica entre paráfrasis, más transparente, en el nivel de la lengua, cuanto más concretas y definidas en el plano referencial están las expresiones lingüísticas. Así se observa en los dos ejemplos siguientes, tomados de nuestro corpus:

(3) Los españoles primitivos usaban de la poligamia, esto es, que tenían a un tiempo muchas mujeres en matrimonio. (Tratado único y singular del origen de los indios occidentales, s. XVII, DAVIES).

(4) ¿Debería recordarles que el chico era un obrero: es decir, una persona que no está para alardes dialécticos, un hombre con otros problemas? (Últimas tardes con Teresa, s. XX, CORDE).

La paráfrasis de (3) constituye una traducción metalingüística (en este caso, una traducción interlingüística vertical), en la que se establece una relación de equivalencia puramente denotativa: traducimos directamente del griego $\pi$ o $\lambda v \gamma \alpha \mu i ́ \alpha$, al castellano poligamia: 'tener muchas mujeres como esposas', con lo que solo se sustituye significante por significante, sin ninguna dificultad a la hora de realizar la paráfrasis, que en este caso corresponde al esquema de la definición del término poligamia. Se trata de una expresión con un significado denotativo, que no tiene sentidos connotativos, sino que es el nombre que se aplica a un referente inequívoco y que está bien definido en la lengua, por lo que la relación de equivalencia no plantea ningún problema (aunque la riqueza semántica de la paráfrasis sea nula). Sin embargo, en (4), cuyo esquema es también una definición de un término (obrero), es más difícil o se percibe menos clara la equivalencia que establece la relación de paráfrasis entre obrero y su definición, ya que el término no está definido en la lengua de manera inequívoca ni se aplica a un referente único y determinado, sino que se constituye como un contenido connotativo que puede presentar a cualquier objeto como designable, dentro de una clase, al que transmite sus sentidos sémicos. Para ver la equivalencia en (4) hay que recurrir al contexto ('obrero $\rightarrow$ clase baja $\rightarrow$ poco instruido $\rightarrow$ práctico $\rightarrow$ con problemas inmediatos $\rightarrow$ que no está para alardes dialécticos') e inferir de ahí la equivalencia, ya que se trata de una definición contextual que explicita aquellos rasgos significativos que convienen a la situación discursiva y al contexto para dar sentido al término que se define.

\section{La reformulación parafrástica y la Pragmática}

En el terreno de la pragmática se hace preciso investigar en qué contextos se puede sustituir una oración A por una oración equivalente B y en qué contextos, no; ya que la reformulación

20 J. A. Martínez López (1997) trata el problema de la sinonimia en unidades léxicas abstractas y concretas, señalando la mayor dificultad que existe en el caso de estas últimas, por la mayor subjetividad en la conceptualización de los estereotipos, que obliga a recurrir a los diferentes usos del signo en el discurso. 
parafrástica entre enunciados presenta un tipo de relación semántica en la que están presentes las diferencias de sentido y los diversos puntos de vista sobre una misma secuencia discursiva, factores todos ellos extralingüísticos. El concepto de reformulación pasa a funcionar, por tanto, no solo en el nivel semántico, sino también en el pragmático. De hecho, como afirma R. Rath (1975), la problemática de la descripción de la estructura de la paráfrasis reside esencialmente en la determinación de las paráfrasis como textos especiales en cuanto que se trata de textos expresados en situaciones concretas y bajo condiciones determinadas del hablante y del oyente. Por ello, no parece posible explicar la relación parafrástica exclusivamente sobre la base de la Sintaxis y la Semántica, aunque, por otra parte, no se pueda renunciar a la inclusión de estos dos niveles de análisis como componentes esenciales en la determinación de la paráfrasis. La situación o contexto concreto de la enunciación y las presunciones mutuas sobre las condiciones de nuestro interlocutor juegan un papel fundamental en todo tipo de comunicación, de modo que, según R. Rath, cuanto menos apoyo pragmático esté a nuestra disposición en el acto de la comunicación, cuanto más dependa la comprensión de una formulación lingüística exclusivamente de los elementos léxicos y gramaticales de la lengua que se usa, más inseguro y más largo será el proceso por el que se establece la comprensión. Y de aquí se deduce la siguiente afirmación aplicada al empleo de la paráfrasis: cuanto menos apoyo situacional y conocimiento pragmático haya, más frecuente será la necesidad del mecanismo de la paráfrasis. En resumen, la paráfrasis, desde este punto de vista, se define como una reformulación discursiva y hay que inscribirla en los estudios semántico-pragmáticos que estudian la lengua en uso, relacionada con otros parámetros externos: los parámetros de la actividad discursiva.

Desde un enfoque comunicativo de la lingüística se estudia el enunciado en sentido amplio, como discurso influido principalmente: a) por los factores individuales del emisor y el receptor, b) por las circunstancias particulares de la situación comunicativa, y c) por las referencias extralingüísticas del significado, es decir, por el contexto extralingüístico como componente conformador del significado. Por otra parte, dentro de la Pragmática, la reformulación parafrástica como actividad discursiva ha interesado de manera especial a los estudios sobre los marcadores del discurso y los mecanismos de cohesión textual.

\subsection{Marcadores del discurso: los reformuladores}

En la organización de un texto o de un discurso se observan expresiones que sirven para estructurar las partes que lo componen, enlazar unos enunciados con otros o un enunciado con el contexto, mostrándose como guías para facilitar al interlocutor la interpretación del discurso. Estas expresiones son los denominados marcadores del discurso. Si bien la reformulación parafrástica puede tener lugar, en los casos en que la equivalencia semántica es fuerte, sin la presencia de un marcador, en muchos casos estos son imprescindibles porque permiten al sujeto unir los diferentes movimientos discursivos (en este caso, establecer los diferentes tipos de relación parafrástica) que quiere dar en el momento de la reformulación. Sobre los marcadores del discurso, R. Rath (1975) los utiliza en su estudio sobre la paráfrasis comunicativa $^{21}$ bajo el nombre de marcadores o indicadores parafrásticos. Considera que determinados casos de relación parafrástica contienen necesariamente un marcador, porque las relaciones textuales existentes entre los miembros del discurso no bastan para establecer

21 También la llama paráfrasis contextual, por su funcionamiento en el ámbito de la comunicación, tanto oral como escrita, como un mecanismo de explicación y precisión retóricas. 
una relación parafrástica reconocible. Es decir, que en muchos casos es el indicador explícito el que de manera exclusiva hace reconocible la relación parafrástica. Y a este tipo de relaciones las llama paráfrasis explícitas ${ }^{22}$. Según este autor, pares de oraciones o unidades de expresión muy diferentes entre sí, que a simple vista no constituyen un discurso parafrástico, pueden contraer relaciones parafrásticas por medio de un marcador o indicador de paráfrasis.

J. Portolés (2001) distingue dos tipos de significado: 1) conceptual, y 2) de procesamiento. Los marcadores del discurso tienen un significado de procesamiento, que guía las inferencias que se han de realizar de los distintos miembros del discurso, es decir, proporcionan unas instrucciones de significado ${ }^{23}$ que varían según los diferentes tipos de marcadores. En general, los marcadores reformuladores son los que tienen instrucciones de formulación: presentan una nueva formulación de un miembro anterior, porque el hablante considera que lo que ha dicho no transmite satisfactoriamente lo que quería decir (su intención comunicativa) y así, el miembro precedente ha de interpretarse a partir del nuevo miembro discursivo. Los distintos tipos de marcadores reformuladores (explicativos, de rectificación, de distanciamiento y recapitulativos) no se comportan del mismo modo, ya que establecen diferentes tipos de relacion -parafrásticas y no parafrásticas-, entre los miembros que conectan. Aquí interesan los reformuladores explicativos, que establecen una relación parafrástica o de explicación entre los miembros del discurso y que, asignando una interpretación nueva más o menos distanciada de lo anterior, establecen una relación de equivalencia semántica entre los enunciados $^{24}$. Los marcadores reformuladores de rectificación, de distanciamiento y de recapitulación se consideran, en cambio, marcadores que establecen relaciones no parafrásticas entre los miembros que conectan. Recordemos que en las relaciones de rectificación no hay equivalencia porque el miembro reformulado corrige de manera explícita lo dicho en el miembro de referencia, invalidándolo o anulándolo; en las relaciones de distanciamiento tampoco hay equivalencia, ya que el segmento reformulado reconsidera lo dicho en el segmento anterior, distanciándose de ello y haciéndolo irrelevante para la comunicación; por último, en las relaciones de recapitulación, los marcadores recapitulativos

22 Frente a las paráfrasis explícitas, las paráfrasis implícitas de R. Rath se reconocen como tales por medio de las concatenaciones y encadenamientos textuales especiales que se dan entre sus miembros. Estas concatenaciones pueden ser, por ejemplo, las correferencias, las sustituciones y las remisiones a elementos ya mencionados. Según este autor, el indicador parafrástico sustituye en la paráfrasis explícita lo que en la paráfrasis implícita es el necesario cúmulo de concatenaciones.

23 J. Portolés establece tres tipos de instrucciones semánticas: a) argumentativas, b) de formulación, y c) de estructura informativa. Independientemente de la clasificación de los marcadores discursivos, un mismo marcador puede compartir en su significado instrucciones de distintos tipos. De esta forma, un marcador reformulador como o sea, además de contener instrucciones de formulación, puede guiar la inferencia de los enunciados en un sentido argumentativo. Así se ve en el siguiente ejemplo, que extraemos del corpus que utilizamos en esta investigación:

(2) "Un teatro tal, después de entretener honesta y agradablemente a los espectadores, iría también formando su corazón y cultivando su espíritu; es decir, que iría mejorando la educación de la nobleza y rica juventud, que de ordinario le frecuenta". (Memoria para el arreglo de la policía de los espectáculos, s. XVIII, $D A V I E S)$. En efecto, desde el punto de vista argumentativo, los dos miembros parafraseados tienen idéntica argumentación (tal... iría, tal... que iría) y conducen a la misma conclusión.

24 M $^{\text {a }}$ A. Martín Zorraquino y J. Portolés (1999) sostienen que, en todos los casos de reformulación, en lugar de lo anteriormente dicho, la nueva formulación es el miembro que se ha de tener presente en la prosecución del discurso. La paráfrasis es un proceso retroactivo en el que el segundo miembro se entiende y se interpreta a partir del primero (al que aclara, enriquece, especifica o amplía conceptualmente), y por lo tanto, también este ha de ser tenido en cuenta para una correcta interpretación, es decir, que la relación parafrástica está sustentada en el principio de dependencia interpretativa. Sin embargo, será la nueva formulación la que resulta relevante para la prosecución del discurso, pues el locutor ha reformulado con una determinada intención de retomar lo dicho antes para volver a expresarlo de manera diferente. 
pueden resumir o reformular por vía parafrástica y no parafrástica: si el miembro reformulado asume los segmentos anteriores por medio de un hiperónimo o término comodín, no habría paráfrasis, o bien la relación parafrástica sería mínima, constituyendo más bien una generalización, pero no una paráfrasis; si lo asume con un término nuevo que añade alguna riqueza semántica, se trataría de recapitulación por vía de la anáfora conceptual, y entonces sí habría paráfrasis, ya que existiría una explicación, que es la función implicada en el concepto de paráfrasis que se tiene en cuenta aquí.

Los marcadores reformuladores explicativos canónicos son (J. Portolés, 2001): o sea, es decir, esto es y a saber; otros, menos frecuentes y menos gramaticalizados, son: en otras palabras, en otros términos, dicho con/en otras palabras, dicho con/en otros términos, con otras palabras, dicho de otra manera, dicho de otra forma, dicho de otro modo, de otro modo. Hay otras expresiones que se comportan como marcadores reformuladores, usadas en diferentes etapas del español, como que quiere dezir, quiere dezir tanto como, quiere tanto dezir como, es tanto como dezir, o lo que es lo mismo, o lo que es igual, como si, esto sería como si, entre otras, que han sido encontradas en la confección del corpus para el presente trabajo.

R. Rath en la obra citada propone la siguiente clasificación de los que él llama marcadores parafrásticos, atendiendo principalmente a su estructura sintáctica ${ }^{25}$ :

1. Grupos nominales: con otras palabras/con mis propias palabras (al. Mit anderen/eigenen Worten); con palabras de poeta (al. Mit den Worten des Dichters); con otra expresión (al. In anderer Formulierung).

2. Grupos participiales: dicho de otro modo/dicho de manera más general/dicho más exactamente (al. Anders/allgemeiner/genauer gesagt); vagamente/prolijamente formulado (al. Vage/umständlich formuliert).

3. Oraciones finales de infinitivo no consecutivas: para repetirlo (al. Um es zu wiederholen); para decirlo más claramente (al. Um es deutlicher zu sagen); para presentarlo con más detalle (al. Um es ausführlicher darzustellen).

4. Oraciones principales estandarizadas (estereotipos): esto es/es decir (al. Das heisst); quiere decir/esto significa (al. Das bedeutet); quiero decir (al. Ich will sagen).

5. Oraciones principales o subordinadas parentéticas: repito (al. Ich wiederhole es); como también puede decirse (al. Wie man auch sagen kann).

6. Grupo participial reducido a un adverbio: de otro modo (al. anders); más claramente (al. deutlicher); de manera más precisa (al. präziser); de manera más abreviada; más abreviadamente; de manera más sucinta; más sucintamente.

Para R. Rath la lista no se agota con estos ejemplos, pero estos son los tipos de realizaciones sintácticas más importantes que pueden presentar los marcadores parafrásticos. Cada marcador, por otra parte, aporta algún rasgo aspectual que modifica la comprensión del discurso. Por ejemplo, en el caso del marcador dicho de manera más general (al. etwas allgemeiner gesagt), este contiene un determinado significado que hace reinterpretar la expresión reformulada desde un punto de vista general, frente a la expresión de partida, que se

25 La clasificación que se presenta es la que propone R. Rath para la lengua alemana; sin embargo, consideramos que sirve perfectamente para la lengua española, ya que acompaña muy bien el esquema propuesto por J. Portolés. 
entiende desde un punto de vista particular ${ }^{26}$. La variedad de formas lingüísticas que pueden presentar los indicadores parafrásticos, en lo que se refiere al contenido, está justificada, según este autor, en la variedad de aspectos potenciales bajo los cuales los enunciados o expresiones pueden ser parafraseados. Sin embargo, por la estructura interna generalsemántica de los marcadores parafrásticos, se puede reconocer una invariante determinada, de tal manera que un marcador parafrástico se construye la mayoría de las veces de forma binaria, conteniendo principalmente dos “momentos" relevantes del mecanismo parafrástico:

(a) Un momento que corresponde al acto del decir (des Sagens), en el que el marcador se puede realizar gramaticalmente de diferentes formas: verbo finito, participio, infinitivo, sustantivo.

(b) Un momento que corresponde a la aspectualización (die Aspektualisierung), que se puede definir como la modificación de la lectura del discurso, en función del marcador empleado. El aspecto puede estar representado por un adverbio, un grupo nominal adverbial o un adjetivo atributivo ${ }^{27}$.

Así, en un marcador como dicho más exactamente (al. genauer gesagt), hay un participio (dicho) que corresponde al momento en que se alude al acto de decir, y hay un sintagma adverbial (más exactamente) que corresponde a la aspectualización o modificación que realiza el marcador sobre el hecho de cosas de las que se habla. Existen casos en los que el marcador está formado solo por el elemento que proporciona la aspectualización (como puede ser el marcador de manera más precisa) y casos en los que ocurre lo contrario, es decir, en los que el marcador se reduce únicamente al momento del decir (como los casos de repito o quiero decir). En casos como este último, en los que el marcador no da más información, hay que considerar el aspecto general de la explicación como motivo para la reformulación o repetición.

\subsection{Cohesión textual}

Como fenómeno que contribuye a la organización del discurso, por medio de los marcadores reformuladores, pero también sin ellos, la reformulación parafrástica se define como uno de los mecanismos de cohesión textual. La relación de equivalencia semántica que se establece entre los miembros discursivos a través de la paráfrasis facilita, por una parte, la coherencia del discurso, por la congruencia que hay entre ellos, así como por la que hay entre ellos y el contexto discursivo; por otra parte, facilita la cohesión, por medio sobre todo de los

26 La generalización es uno de los esquemas parafrásticos que R. Rath propone en su definición de paráfrasis, aunque no explica en qué consiste dicho modelo, al decir que la relación parafrástica se da cuando en enunciados o expresiones consecutivas existe de manera evidente una semejanza o igualdad (identidad), cuando por tanto los hablantes expresan lo mismo o algo semejante, con el propósito de contribuir a la comprensión del discurso, de modo que repiten su discurso desviándolo, profundizándolo, precisándolo o generalizándolo. Un ejemplo en español de paráfrasis por generalización, que tomamos de nuestro corpus podría ser el siguiente:

(3) "Que constituyen el desfallecimiento, o sea lo que generalmente se dice "encontrarse mal"'. (Tratado de higiene escolar: guía teórico-práctica, s. XIX, DAVIES).

La generalización se podría definir como una explicación por vía hiperonímica o por medio de palabras comodines y términos de función similar, que abarcan el significado del miembro de referencia, pero no aportan nada más, es decir, implican un enriquecimiento y un margen de creación mínimos. Por lo tanto, dado que la expresión encontrarse mal es el hiperónimo de desfallecer, la paráfrasis es prácticamente inexistente.

27 La aspectualización del marcador a la que se refiere R. Rath correspondería a las instrucciones semánticas de J. Portolés, aunque el concepto de R. Rath se aplicaría de manera más específica para cada marcador. 
marcadores, que indican las relaciones entre los elementos vinculados. Según R. Rath (1975), la paráfrasis, tanto implícita (sin marcador parafrástico), como explícita (con marcador parafrástico) se caracteriza por ser un elemento que contribuye a la estructuración del texto, con el objetivo principal de facilitar la comunicación. Junto al mecanismo de la paráfrasis distingue otros mecanismos, no menos importantes, de estructuración del texto, que también sirven al éxito de la comunicación, aunque con algunas diferencias respecto de la paráfrasis. Así, por ejemplo, el comentario, operación por la cual el que da su opinión emite una valoración, verdadera o falsa, sobre un determinado contexto de circunstancias. La paráfrasis, en el decurso de la comunicación, tiene una "función de puente" (R. Rath, 1975), ya que como repeticiones específicas, las paráfrasis constituyen la base para la introducción gradual de contenidos nuevos o contenidos que modifican el discurso precedente. Por esta misma razón, la explicación que caracteriza la paráfrasis implica siempre, en mayor o menor grado, un enriquecimiento, un plus semántico, y por tanto, de información. En opinión de este autor, es precisamente el carácter lineal ${ }^{28}$ de la comunicación, más que el propio déficit de comunicación inherente a la lengua, el factor que condiciona el empleo de los mecanismos parafrásticos, cuyo resultado final garantiza el éxito de la interacción comunicativa.

Por otra parte, la cohesión textual en el marco de la reformulación parafrástica se ve reforzada por otros mecanismos más clásicos de cohesión, como son las relaciones semánticas tradicionales (sinonimia e hiponimia) y la reiteración por medios léxicos (acumulación de elementos pertenecientes a un mismo campo léxico). Esquemas de reformulación como la recapitulación (nueva formulación que recoge todo lo dicho en varios segmentos anteriores), que en algunos casos es parafrástica, y también la denominación (el fenómeno inverso a la definición), contribuyen de manera especial a la cohesión textual, de manera similar a como lo haría el mecanismo de la anáfora conceptual o encapsulación anafórica, procedimiento basado en la nominalización del miembro de referencia ${ }^{29}$.

\section{La reformulación parafrástica y la Semántica}

En la semántica teórica, la paráfrasis se ha estudiado como un caso de sinonimia, en concreto como un tipo de sinonimia sintagmática. La sinonimia es la relación entre dos o más palabras asociadas a un contenido parecido o igual (sinonimia léxica), que son intercambiables en todos los contextos. Cuando la relación se da, no entre palabras, sino entre sintagmas $u$ oraciones, se puede hablar de sinonimia sintagmática ${ }^{30}$, relación que está vinculada evidentemente al contexto lingüístico. Se puede presentar:

a) entre un vocablo y un sintagma equivalente (léxico-sintaxis): comprar y hacer la compra

b) entre dos expresiones libre(s) y/o idiomática(s) (léxico): pedir peras al olmo y pedir lo imposible

28 Consúltese también en A. Penas (2009b: 121-124), todo el proceso que conlleva: continuidad $\rightarrow$ sucesividad $\rightarrow$ linealidad $\rightarrow$ jerarquía $\rightarrow$ endocentricidad.

29 Véase R. González Ruiz (2009).

30 También se podría llamar traducción intralingüística, ya que se pretende sustituir lo dicho en una lengua por medio de otra expresión "que signifique lo mismo" en la misma lengua. Si en la traducción interlingüística se buscan equivalentes o sinónimos en una lengua diferente; en la traducción intralinguiística se buscan equivalentes o sinónimos dentro de una misma lengua. La clasificación que se presenta sobre las diferentes realizaciones sintácticas en que puede manifestarse la sinonimia sintagmática está tomada de A. Penas (2008/2009b). 
c) entre oraciones equivalentes: una oración activa y su correspondiente pasiva (sintaxis): vendió el libro y el libro fue vendido

Ahora bien, desde el plano sintagmático se hace necesario distinguir entre dos tipos de reformulación: 1) entre frases u oraciones, y 2) entre enunciados; siendo el primer caso, en teoría, el que más se acerca a la sinonimia, al cumplir las oraciones las propiedades de la univocidad, intercambiabilidad en cualquier contexto, la invariabilidad referencial y el recorrido onomasiológico. En la práctica, sin embargo, hemos visto que la supuesta sustitución de una oración por otra no funciona en todos los contextos, ya que las referencias extralingüísticas y los diferentes sentidos y puntos de vista de una oración tienen un papel fundamental en su actualización discursiva, cuando ya se convierte en un enunciado.

El primer tipo de reformulación (el realizado entre frases y oraciones) se plantea desde el ámbito de la lengua tomando exclusivamente el significado denotativo de los signos linguiísticos, dejando de lado los valores añadidos y las aportaciones pragmáticas de que son objeto las oraciones al funcionar en un discurso. Esta supuesta equivalencia lógico-semántica se ve afectada por los mismos problemas que la sinonimia: la imposibilidad de demostrar la total identidad de significado, el debate entre la relación de identidad parcial o total, la dicotomía entre la identidad o la semejanza de significados, o la cuestión de si la lengua se permite el lujo de disponer de varias expresiones para significar lo mismo. Al igual que ocurre con la sinonimia léxica, se podría simplificar el concepto de la sinonimia sintagmática a una relación de semejanza, de afinidad significativa entre expresiones diferentes, susceptibles de referirse al mismo significado (no a la misma realidad). Así, se hablaría de un concepto amplio de sinonimia sintagmática, en el que las oraciones sinónimas tienen una parte de significado común, que hace posible su conmutación y que permite variar y acumular su expresión, y una parte diferencial, que contribuye a dar precisión y propiedad al uso de las oraciones en el discurso ${ }^{31}$. Según R. Trujillo (1996), las palabras y los textos pueden usarse sinonímicamente, cuando las diferencias semánticas que introducen no sobrepasan el límite de equivalencia permitido por el contexto.

El segundo tipo de reformulación (el llevado a cabo entre enunciados) privilegia el plano onomasiológico en el acto de elección comunicativa, creación y/o adecuación lingüística y contextual, no tratándose solo de una cuestión de conveniencia estilística, sino también y sobre todo de una cuestión semántico-pragmática, ya que cuando el hablante elige una formulación en lugar de otra, lo hace porque su intención comunicativa no podría expresarse de otra manera.

En la lengua, los conjuntos parafrásticos se constituyen por medio de cuatro mecanismos, según la quadripertita ratio clásica ${ }^{32}$. Partiendo de la oración Podemos pedir a la gente que haga una colecta, se distingue entre:

a) Añadido (adiectio): Podemos pedir ayuda a la gente para hacer una colecta

b) Borrado (detractio): Podemos pedir una colecta

c) Desplazamiento (transmutatio): Que haga una colecta podemos pedir a la gente

d) Sustitución (inmutatio): Es posible pedir a la gente que haga una colecta

Estos mecanismos se pueden presentar también mezclados, como en el caso de Para hacer una colecta podemos pedir ayuda a la gente, donde se emplean los mecanismos de la adiectio

31 Este es grosso modo el concepto de sinonimia de B. García-Hernández (1997a).

32 La clasificación y los ejemplos están tomados de A. Penas (2008/2009b). 
y la transmutatio. Lo importante es señalar que, aunque equivalentes en cuanto a la forma, el mensaje que transmiten estas oraciones puede variar significativamente. A nivel semánticológico todas las paráfrasis responden al mismo significado, lo que constituye la invariante común a una familia de oraciones equivalentes, pero hay que tener en cuenta las diferencias de sentido o variantes pragmáticas, que se pueden producir en función de la topicalización, la focalización, la linearización y la connotación. En este punto, la paráfrasis pasa del contexto linguístico (sintagmático), al contexto extralingüístico (pragmático). Teorías más recientes, desde un enfoque comunicativo, apuntan a la necesidad de tener en cuenta estas diferencias, que en ocasiones imposibilitarán la sustitución oracional.

En lo que se refiere a la connotación, se hace preciso destacar que su estudio no queda fuera de la significación, sino que es un complemento indispensable para el análisis semántico y sobre todo componencial del significado ${ }^{33}$. Aunque tiene su lugar predilecto en el discurso literario, la connotación prolifera también en el lenguaje cotidiano e incluso en el discurso científico, de modo que los dos tipos de valores semánticos (denotativo y connotativo) no son exclusivos sino complementarios. La connotación es un concepto productivo en sí mismo, por la utilidad de que da prueba; y también productivo porque desemboca en dos problemas importantes, que son la polisemia textual y la subjetividad de la captación y verbalización del referente ${ }^{34}$.

También desde la lingüística de la comunicación, a la codificación y descodificación a través del código lingüístico, se suma el concepto de interpretación de los enunciados, que no se reduce a la biunivocidad isomórfica entre forma y sentido, sino que implica además fenómenos de plurivocidad, semasiológicos (polisemia y homonimia) y onomasiológicos ( sinonimia y paráfrasis $^{35}$ ), dentro del proceso más amplio de la ambigüedad. Un mensaje ambiguo es una secuencia de signos a la que, fuera de todo contexto, es posible asignar dos o más interpretaciones ${ }^{36}$. La ambigüedad solo existe para el interpretante, y los valores intermedios que surgen de ella se pueden considerar paráfrasis en cuanto que vienen a ser diferentes interpretaciones de una misma intención de comunicar.

En un determinado contexto, el hablante puede considerar sinónimas o, mejor dicho, equivalentes pragmáticamente, oraciones como Llueve y No saldremos de excursión, porque

33 Véase A. Penas (2008 y 2009c). La connotación se pone al servicio de la denotación ya que, al afectivizarla, favorece una mayor adhesión al mensaje y, multiplicando el sentido, aumenta su caudal semántico. En todo texto coexisten los sentidos denotados y los valores connotados, engendrados por medio de mecanismos evocadores y asociativos, internos al enunciado, que constituyen el conjunto de las estructuras paradigmáticas y sintagmáticas que definen el idiolecto textual.

34 B. Pottier (1976 y 1993) define el semema como el conjunto de semas articulado en torno al semantema (conjunto de semas específicos), clasema (conjunto de semas genéricos) y virtuema (conjunto de semas virtuales o potenciales). En el virtuema de las palabras se ubica la connotación, valores fijados que están incorporados a la lengua, de modo que podemos usar, por ejemplo, locomotora, para designar cualquier entidad provista de fuerza y potencia, pues ha incorporado estos valores en su virtuema, y consecuentemente podemos decir: "La construcción ha sido la locomotora de la economía en España".

35 Según B. Pottier (1993), una intención conceptual puede decirse de varias formas, es decir, por medio de "una infinidad de paráfrasis", que van de la "palabra justa" (el ortónimo) a la perífrasis lúdica. Así, el párpado del ojo será para el lexicógrafo "piel móvil que puede cubrir el ojo"; para el crucigramista "cerrado por la noche". Ante un acontecimiento observable, podemos, a lo largo de su descripción, emplear lexías como partir, salir, marcharse, irse, dar un portazo, que están en relación de parasinonimia, es decir, que tienen al menos un sema en común (el núcleo sémico).

36 Para S. Gutiérrez (1989), además de la ambigüedad, se pueden citar la indeterminación (falta de información) y la vaguedad (límites designativos imprecisos), que también se engloban dentro de la plurivocidad del enunciado. Estos son ejemplos de "restauración" de la estructura semántica por parte del receptor, según M. Prandi (1995), que incluye también la reintegración de los constituyentes suprimidos por el fenómeno de la elipsis. 
cuando "dice" Llueve, "quiere decir" No saldremos de excursión (desde el plano de la intención comunicativa, es decir, del "querer decir"). Estas oraciones no se pueden considerar equivalentes o sinónimas per se, a no ser que busquemos el contexto en el que se pueden interpretar como tales, contexto que está formado por una serie de referencias de carácter extralingüístico. En este caso, por ejemplo, que hay una intención planeada de salir de excursión, que la excursión es al aire libre, por lo que el buen tiempo es una condición asumida, existe un acuerdo con el receptor y un conocimiento compartido, etc. La equivalencia que se da es más situacional, referencial, que semántica, y podría definirse como paráfrasis pragmática ${ }^{37}$. En estos casos, el mecanismo de la relación parafrástica funciona de manera similar a como lo hacen las implicaturas de P. Grice, en las que lo implicado depende de lo dicho y de otro tipo de factores que gobiernan la conversación. Las implicaturas son significados que no dependen siempre del significado convencional de las palabras emitidas, sino de que los hablantes presupongan la vigencia del principio de cooperación. Igual que ocurre en la paráfrasis pragmática, para explicar estas implicaturas (o equivalencias, en el caso de la paráfrasis) no hay que analizar las propiedades semánticas de las palabras, sino los principios que regulan la conversación. Por ello, reciben el nombre de implicaturas conversacionales $^{38}$.

\section{La paráfrasis como un caso de sinonimia sintagmática}

La descripción de la paráfrasis según su vínculo con los sujetos y con las situaciones discursivas la convierte en una operación de reformulación, cuyo funcionamiento supone aceptar que existe un texto fuente $(T)$, a partir del cual, mediante la reformulación, se obtiene otro texto de llegada $\left(T^{\prime}\right)$. Mientras que la sinonimia implica solo un recorrido onomasiológico, en la paráfrasis se descubre un doble proceso: semasiológico, de interpretación de $T$; y onomasiológico, de producción de $T$ '. La reformulación parafrástica es, por tanto, una interpretación del contenido de $T$, o una fase intermedia entre $T$ y $T$, en la que se produce una transferencia del contenido $C$ asociado a $T$ a un contenido $C^{\prime}$ asociado a $T$ '. En esta transformación del contenido $C$ en $C$ ' opera una selección de los rasgos de $C$ por parte del sujeto de la enunciación, selección que está condicionada por factores discursivos y del contexto extralinguiístico. Esta selección puede ser cuantitativa y cualitativa. En el primer caso, la relación parafrástica puede variar entre el desarrollo o la condensación de $T$; en el segundo caso, la paráfrasis puede oscilar entre el plagio total o la reformulación absoluta. Desde el momento en que se reformula, hay una mínima transformación en el contenido del

37 M. Prandi (1995) la describe como una "forma radical de paráfrasis", que se sirve como criterio de equivalencia de la intención comunicativa del locutor y que requiere un desarrollo inferencial. Así, en los ejemplos que propone, entre Mañana no hará bueno: Mañana no iremos al faro, o entre Llueve: Hay que plantar las rosas. De cada una de las primeras formulaciones se podría inferir un mensaje completamente diferente a partir del mismo contenido, por lo que es necesario un proceso inferencial por el que se asocie al contenido del enunciado aquella información relevante, seleccionándola del contexto de la enunciación, para orientar la interpretación hacia el mensaje que se quiere realmente comunicar. Esta consideración de la paráfrasis contrasta con la de R. Rath (1975), para quien la "paráfrasis pragmática", del tipo Hace corriente: Cierra la ventana, corresponde a otro tipo de formulaciones alternativas, aunque no explica cuáles. Por lo tanto, para Rath estas relaciones entre oraciones no son parafrásticas. Por su parte, A. Penas (2008/2009b) propone el siguiente ejemplo: Necesitaba arreglar sus botas: Llevaba unas botas muy estropeadas, donde, para considerar una relación parafrástica entre las dos oraciones, es preciso un contexto y unas condiciones interpretativas como: saber que 'lo que está estropeado tiene que ser arreglado', o 'si necesitaba arreglar sus botas es que estaban muy estropeadas', y 'si las botas estaban muy estropeadas, estas necesitaban ser arregladas'.

38 G. Reyes, E. Baena y E. Urios (2005). 
nuevo texto con respecto al contenido del texto fuente. Es precisamente esta transformación, por mínima que sea, la que implica que la paráfrasis discursiva sea por regla general una relación no transitiva, a diferencia de la sinonimia, que siempre es transitiva.

Partiendo de la explicación como proceso general que conlleva toda relación parafrástica y cuyo resultado implica siempre, en mayor o menor grado, un plus o enriquecimiento semántico respecto del texto fuente, se pueden distinguir los mecanismos por los que aquella opera y los principales esquemas que se derivan de ellos, en función de la selección que realiza el sujeto de los rasgos que configuran el contenido del texto fuente. Así, cuando la paráfrasis opera por expansión o desarrollo de $T$, esta puede consistir en una definición ${ }^{39}$, si el miembro reformulado explicita los rasgos de significación que configuran el semema de una palabra o expresión; o en una precisión ${ }^{40}$, cuando el miembro reformulado determina con mayor exactitud el miembro de referencia, especificando algunos de sus rasgos de significación. Si se establece la paráfrasis por reducción o condensación de $T$, esta puede constituir una denominación ${ }^{41}$, cuando todos los rasgos significativos señalados en el miembro de referencia quedan reducidos a un término; un resumen ${ }^{42}$, si el miembro de referencia se recoge o sintetiza mediante una nueva formulación abarcadora, que comparte rasgos de contenido con lo expresado en aquel; o una recapitulación ${ }^{43}$, que funciona igual que el resumen, pero con un segmento de referencia colectivo, y que también será parafrástica únicamente cuando se realice por vía de la anáfora conceptual, es decir, mediante un término o expresión que abarque semánticamente lo dicho, pero además enriqueciéndolo. En la paráfrasis por condensación incluiríamos la generalización ${ }^{44}$, esquema propuesto por R. Rath (1975), que no consideramos parafrástico cuando supone una explicación por vía hiperonímica o por medio de palabras comodines que sean tan generales que abarquen el significado del miembro de referencia, pero sin aportar nada más, es decir, aquellos casos en los que la paráfrasis resulte inexistente. Asimismo, no consideramos como relación de reformulación parafrástica aquella que opera por equiparación de los rasgos ${ }^{45}$ semánticos de $T$ y $T$ ', pues en este caso solo caben la traducción interlingüística (vertical u horizontal) y la traducción intralingüística (la sustitución sinonímica), que implican una equivalencia léxica o una equivalencia de código, pero no una explicación con un enriquecimiento semántico.

39 (4) "Esso mismo faz a la otra a que dizen congelamiento, que quiere dezir tanto como atomecimiento de los miembros por razon de friura". (Lapidario, s. XIII, CORDE).

40 (5) "El término neoclásico tiene su origen en las convicciones manifestadas por los principales críticos y poetas de la época, para quienes la teoría y la práctica literaria debían seguir los modelos establecidos por los principales escritores griegos y romanos. Dicho de otro modo, que los escritores habían de centrarse en determinados modelos y no en características individuales". (Crítica literaria, s. XX, DAVIES).

41 (6) "Otro equipo de la Universidad de Iowa ha encontrado una prueba real de la existencia de "un complejo proceso de señales no conscientes', o dicho en otras palabras, de la intuición”. (El Mundo-Salud, s. XX, CORDE).

42 (7) "En todo lo demas no puede quitarse la jurisdision á los Obispos, y assí solo en quanta á que el deputar á los Regulares á estos ejercicios sea por medio de sus Prelados sin Lizencia de el Ordinario, que es lo mismo que no necesitar de Colacion". (Compendio bulario índico, s. XVII, CORDE).

43 (8) "El rubio hipopótamo Exoristo habíales arrebatado a dos sirvientes tres botellas de champaña, otra de chartres, otra de coñac y las sendas copas y la cubeta para el hielo; o, lo que es lo mismo, que les dejó 'en cuadro' las bandejas". (Jarrapellejos, s. XX, CORDE).

44 (9) "[...] que constituyen el desfallecimiento, o sea lo que generalmente se dice "encontrarse mal"". (Tratado de higiene escolar: guía teórico-práctica, s. XIX, DAVIES).

45 (10) "Ése es el propio plazo para despertar y levantarse el hombre, que allá dice la ley: 'Dies interpellat pro homine', que quiere decir en nuestro romance castellano que el día interpela a favor del hombre". (Coloquios de Palatino y Pinciano, s. XVI, CORDE). 


\section{Análisis de los diferentes esquemas y modelos de reformulación parafrástica}

La muestra de los cuarenta ejemplos de paráfrasis analizados para el presente artículo nos ha permitido extraer algunas conclusiones que podrían ayudar a entender mejor los mecanismos de funcionamiento de la reformulación parafrástica. Los ejemplos analizados, tomados de los diferentes corpora del español (CREA, CORDE y DAVIES), y seleccionados a partir de una muestra previa más amplia de 395 textos, han sido clasificados en literarios y no literarios en función del tipo de texto del que han sido tomados. Igualmente, se ha realizado un estudio diacrónico de los mismos, ya que la muestra abarca desde el siglo XII a principios del siglo XXI, conformados, para facilitar el análisis de la muestra seleccionada, en cinco edades: Edad Medieval (siglos XII y XIII); Edad bajo medieval-prerrenacentista (siglos XIV y XV); Edad de Oro (siglos XVI y XVII); Edad Moderna (siglos XVIII y XIX); y Edad Contemporánea (siglos XX y principios del XXI). El análisis se ha llevado a cabo en base a dos elementos fundamentales: a) la forma, donde se estudian los marcadores reformuladores, y b) el contenido, donde incluimos, tanto los mecanismos semánticos que hemos llamado de proceso, y que hemos definido como aquellos por los que opera la reformulación parafrástica; como los mecanismos semánticos de resultado, que constituyen la finalidad para la que se ha empleado la paráfrasis en el discurso.

Si bien la relación parafrástica puede expresarse y operar sin la presencia de los marcadores reformuladores, y en este caso nos hallaríamos ante la llamada por R. Rath (1975) paráfrasis implícita, la estructura de la paráfrasis, en los ejemplos que constituyen el corpus para la presente investigación, consta de tres partes: 1) el segmento de referencia o enunciado que se explica por medio de la paráfrasis; 2) el marcador de reformulación explicativo (J. Portolés, 2001) o indicador parafrástico (R. Rath, 1975), como el tipo de conector discursivo empleado, que contiene unas determinadas instrucciones semánticas que guían las inferencias que se han de realizar de los distintos miembros discursivos; y 3) el segmento reformulado o enunciado introducido por el marcador reformulador, que desarrolla, define, aclara, resume, recapitula, etc., el segmento de referencia. Asimismo, hemos preferido prescindir de los casos de paráfrasis basados en una equivalencia designativo-referencial, ya que en estos casos la identidad, al estar basada únicamente en el referente y sus asociaciones con las cosas designadas, no ofrece posibilidades de estudio de las estructuras semánticas de los elementos que conforman la paráfrasis. Este tipo de reformulación exigiría otro tipo de análisis, basado, no en procesos y mecanismos semánticos, sino en la semiótica, la cultura, el contexto y el campo retórico de las diferentes épocas. Ofrecemos un ejemplo, tomado del corpus utilizado para la investigación, con el fin de ver más claro este tipo de equivalencia:

(5) Semejóli que vido un ome blanqueado, como si fuesse clérigo de missa ordenado. (Vida de Santo Domingo de Silos, s. XIII, CORDE).

Se observa que la equivalencia establecida por el marcador reformulador como si, entre los segmentos un ome blanqueado y clérigo de missa ordenado, es una equivalencia únicamente referencial, semiótica, producto de una convención social de la cultura occidental de la época, en la que por norma el clérigo debía vestir para la misa una sobrepelliza de lino y muy blanca. El proceso de identidad está basado principalmente en el concepto de campo retórico de $\mathrm{S}$. Arduini (2000), que incluye la cultura, las creencias y las convenciones fijadas en una determinada sociedad en una época concreta. 


\subsection{Los marcadores reformuladores explicativos}

En los ejemplos del corpus analizado se han encontrado, tanto casos de marcadores parafrásticos canónicos (J. Portolés, 2001): esto es, es decir, es a saber, como ejemplos de marcadores parafrásticos no canónicos: dicho de otro modo, dicho en otras palabras y en otros términos. Además, hemos hallado otras expresiones que pueden funcionar como marcadores reformuladores explicativos, usadas en diferentes épocas del español: que quiere dezir, quiere dezir tanto como, quiere tanto dezir como, es tanto como dezir, lo que es lo mismo, lo que es igual, como si, bien así como si, ca y esto sería como si.

Es interesante observar cómo el adverbio causal $c a$, presente en textos de la que hemos considerado aquí Edad Medieval, funciona como un marcador parafrástico:

(6) La quarta es por adopçión que quiere tanto dezir como porhijamiento. E esto seria como si el auuelo departe dela madre prohijase ${ }^{46}$ asu nieto $c a$ en tal manera caydria el nieto en poder de tal auuelo. (Siete partidas, s. XIII, DAVIES).

La equivalencia que establece el marcador ca entre los segmentos el auuelo departe dela madre prohijase asu nieto y en tal manera caydria el nieto en poder de tal auuelo, tiene un sentido causal y argumentativo, en cuanto que si el abuelo "porhija" a su nieto, este "cae en poder" del abuelo. Se ha comprobado a través del funcionamiento de esta partícula causal, que la relación que establece entre los segmentos discursivos es al mismo tiempo: a) parafrástica, es decir, de equivalencia semántico-pragmática; y b) causal, ya que hay una relación de causa-efecto entre los dos segmentos discursivos relacionados.

Por otra parte, en (6) podemos distinguir una relación de reformulación discursiva encadenada, mediante la cual podemos observar el funcionamiento de dos marcadores reformuladores frecuentes en los siglos XII y XIII: a) que quiere tanto dezir como; y b) esto seria como si. En el primer caso, el marcador pone en relación los miembros discursivos por adopción y porhijamiento, entre los que se establece una relación parafrástica que opera por el mecanismo de la sinonimia. En el segundo caso, existe una relación discursiva de reformulación lingüística entre la expresión porhijamiento y el enunciado el auuelo departe dela madre prohijase asu nieto, ambos segmentos conectados por el marcador esto seria como si. Entre estos segmentos hay una relación de reformulación lingüística, pero no parafrástica, sino de ejemplificación. El "porhijamiento" puede darse de diversas maneras, una de ellas es el caso en el que el abuelo materno adopte al nieto, pero no sería la única. Este enunciado, por tanto, constituye solo un ejemplo que sirve para argumentar el significado de 'adopción' que tiene el término "porhijamiento", pero no se presenta como su equivalente semántico.

En los siglos XII y XIII no se registra la mayoría de los marcadores reformuladores considerados canónicos, con la excepción de esto es, que empieza a aparecer en el siglo XIII, como se comprueba en el Corpus Diacrónico del Español. No obstante, otras expresiones, que funcionan como marcadores parafrásticos, son frecuentes en los primeros siglos de la historia del español: es el caso de que quiere tanto dezir como y que quiere dezir. Otro de los marcadores reformuladores aparecidos en el corpus analizado lo constituye la expresión es a saber, que se podría definir como una variante del marcador a saber, considerado uno de los

46 Porhijamiento: Prohijamiento; Lat. Adoptio. Prohijar: Adoptar y declarar por hijo al que lo es de otro naturalmente. (Diccionario de Autoridades, 1737). Adoptar: Recibir, y admitir por hijo al que naturalmente lo es de otro. Viene del Latino Adoptare, que significa esto mismo. (Diccionario de Autoridades, 1726). 
conectores reformuladores explicativos canónicos, según la clasificación de los marcadores discursivos que propone J. Portolés (2001). Este marcador se usa a menudo para introducir un segmento que constituye una enumeración de conceptos relativos a lo expresado en el enunciado anterior. Sin embargo, en determinados contextos discursivos, puede realizar la función de indicador parafrástico:

(7) Que, buelto en castellano, dize: "Porque si cessa la dotrina y arte de las armas, en ninguna cosa difiere el villano del soldado, por ser antigua y prudente sentencia, que todas las artes consisten en meditación”. En lo qual significó Vegecio lo mismo que si más claramente dixera: todas las artes tienen necesidad de imitación y estudio, es a saber, no se saben naturalmente, sino aprendiéndolas y ejercitándolas. (Noticia general para la estimación de las artes, s. XVII, DAVIES).

En este caso, la relación parafrástica opera por diversos mecanismos: a) hay una relación metonímica de causa-efecto entre los miembros de la reformulación, pues el hecho de que las artes no se saben naturalmente, sino aprendiéndolas y ejercitándolas, constituye la causa de que sean necesarios la imitación y el estudio; b) la equivalencia entre necesidad de imitación y estudio y no se saben naturalmente, se produce por oposición entre "saber naturalmente" y "saber por medio de la instrucción", que se constituye como una especie de oposición entre adquisición y aprendizaje; y c) existe otra metonimia con paralelismo, en la que se toman los instrumentos por las acciones: imitación por exercitar; estudio por aprender.

Hay una serie de marcadores parafrásticos, considerados no canónicos, que se hallan en los ejemplos analizados, tanto de los textos literarios, como de los no literarios, a partir de la Edad Moderna. Es el caso de dicho de otro modo, dicho en otras palabras y en otros términos. En el Corpus de Davies, el marcador en otros términos no se registra en el siglo XVII, y consta en total en seis documentos del siglo XVIII, de los cuales solo en dos cumple la función de conector parafrástico. En el Corpus Diacrónico del Español, este marcador se registra en cinco documentos del mismo siglo, tres de los cuales con valor de reformulador explicativo. Es a partir del siglo XIX cuando este conector aparece con más frecuencia. Respecto de la expresión dicho de otro modo, que se incluiría, siguiendo la clasificación de los indicadores parafrásticos que propone R. Rath (1975), dentro de los llamados "grupos participiales", no aparece en el CORDE hasta el siglo XIX, en el que se recogen tan solo cuatro casos. En el siglo XX aparece ya en 84 documentos; sin embargo, la cifra sigue siendo reducida si se compara con la frecuencia que presentan los marcadores canónicos. Por último, el marcador dicho en otras palabras no consta en el CORDE hasta el siglo XX, en el que se recogen seis casos, a diferencia del marcador dicho de otro modo, que aparecía ya en el siglo $\mathrm{XIX}$, y cuya frecuencia en el siglo XX es mucho mayor.

\subsection{Mecanismos semánticos de proceso}

Los mecanismos semánticos por los cuales opera la paráfrasis, según hemos podido comprobar en los ejemplos analizados, son varios: anáfora conceptual, antonimia, antonomasia, denotación, connotación, elipsis, hendíadis, hipérbole, hiperonimia-hiponimia, ironía, metáfora, metonimia, sinécdoque, sinonimia, quasisinonimia, antítesis, pleonasmo, polisemia y simbología. Asimismo, se han observado determinados mecanismos formales que contribuyen al proceso de la equivalencia semántica, al establecer una equivalencia sintáctica entre los miembros de la paráfrasis, como son los paralelismos lineales y los cruzados o quiasmos. 
La relación parafrástica puede operar, bien mediante un conjunto de mecanismos semánticos, bien mediante un solo mecanismo, que se presenta como el único agente del proceso de la reformulación parafrástica. Igualmente, hemos observado que hay determinados mecanismos que nunca se presentan de forma autónoma como únicos responsables de la paráfrasis, y son la antonomasia, la hipérbole y la polisemia, que siempre acompañan a otros procesos que tienen una mayor autonomía en el establecimiento de la paráfrasis y son más frecuentes, como la metáfora, la metonimia, la sinécdoque, la sinonimia, la antonimia y la anáfora conceptual. En el caso de la connotación, esta puede aparecer como único mecanismo semántico, cuando la equivalencia se deduce de un proceso de inferencia contextual, es decir, como equivalencia pragmática:

(8) [...] sino el hecho mismo de introducir al chico en un clima intelectual, en aquellos centros nerviosos y teorizantes que según el estado de depresión o de exaltación del grupo se traduciría en ganas de desconcertarle o de maravillarle. ¿Debería recordarles que el chico era un obrero: es decir, una persona que no está para alardes dialécticos, un hombre con otros problemas? (Últimas tardes con Teresa, s. XX, CORDE).

El resultado de la paráfrasis de (8) es una definición contextual que se apoya principalmente en las connotaciones del término que se reformula (obrero), además de en otros factores socioculturales y de contexto histórico.

Existen varios mecanismos que pueden establecer por sí solos la equivalencia semántica de la paráfrasis: es el caso de la anáfora conceptual, la metáfora, la metonimia y la sinécdoque. Veamos un ejemplo de cada uno de ellos:

(9) [...] derecho que ha de auer el obispo de los clerigos de su obispado que son estos: que deuen venir quando los llamaren a synodo: \& soterrar los muertos: \& fazer proçession leyendo el perlado en el lugar: \& en darle catredatico cada año que es dos sueldos de la moneda mas comunal que ay en la tierra: y la terçera y la quarta parte de las mandas que los onbres fazen a los clerigos a sus finamientos segund que es costumbre a cada lugar: \& otrosy en dar le la terçia o la quarta parte de los diezmos o procuraçion \& posada: que quiere tanto dezir commo darle la despensa. (Siete Partidas de Alfonso X, s. XV, CORDE).

La anáfora conceptual es el mecanismo por el que se establece la paráfrasis en (9), que tiene como segmento de referencia un enunciado compuesto de tres elementos: 1) dar le la terçia o la quarta parte de los diezmos; 2) [dar le] procuraçion; y 3) [dar le] posada, que están contenidos en el enunciado reformulado, que los abarca, darle la despensa, donde despensa es un sintagma nominal anafórico que recoge y etiqueta, enriqueciendo, los tres conceptos expresados en el enunciado anterior.

(10) Porque meditando un día aquellas palabras del Salmo 71: "Honorabile nomem forum coram illo"; venerable es el nombre de los justos delante del Señor, quedéme, dice, adormido (esto es, admirado con gran suspensión de espíritu), viendo el modo de respeto (si así se puede decir) con que la Majestad de nuestro gran Dios y Señor mira a sus siervos y los trata. (Crónica del Reino de Chile, s. XVI, DAVIES).

En (10), la paráfrasis opera mediante la metáfora, ya que se dice adormido, no como efecto del sueño, en su sentido literal de 'quedarse dormido', sino en el sentido de 'quedarse admirado, pasmado', como paralizado por el efecto de una gran emoción. Por otra parte, para que admirado valga como equivalente de adormido y pueda realizarse la analogía, se 
menciona el sema 'con gran suspensión de espíritu', que es el rasgo que conecta con adormido y facilita la comparación.

(11) Secosse el mio paladar assi como tiesto \& mi lengua ayuntosse amios paladares \& trayst me al poluo de muert: esto es fasta cerca del sepulcro. (Salterio, s. XIII, DAVIES).

En (11), la metonimia es el único mecanismo semántico que opera en el proceso de la paráfrasis, mediante el empleo del continente (el sepulcro) por el contenido (la muerte). La muerte es el término abstracto, entendiendo que se ha producido, en primer lugar, un cambio de lo particular (los difuntos que están en los sepulcros) a lo general (el difunto como habitante del sepulcro); y en segundo lugar, de lo concreto (el difunto) a lo abstracto (la muerte).

(12) Todos tres son acordados los del Campeador que cada uno d'ellos bien fos ferir el so.

Fevos de la otra part los ifantes de Carrión, muy bien aconpañados, $c a$ muchos parientes son.

(Poema de Mio Cid, s. XII, CORDE).

La equivalencia semántica entre los segmentos enlazados en (12) por el marcador $c a$, muy bien aconpañados y muchos parientes son, se produce mediante la sinécdoque de base metonímica (causa-efecto), expresando la parte (muchos parientes) ${ }^{47}$ por el todo (muy acompañados $)^{48}$.

Además de los mecanismos citados, hemos comprobado que también otros pueden soportar por sí solos la relación de equivalencia, si bien su empleo es mucho menos frecuente: se trata de la elipsis, la antítesis y la ironía, como se comprueba en los siguientes ejemplos:

(13) Quando Virginius ovo publicado esta cosa, la muchedumbre del pueblo le dixo asy a alta voz que ellos non le fallescerían punto, nin a su dolor nin a su libertad. Otrosí los de la toga que eran con él venidos [que quiere dezir, omes vestidos de togas, que son vestiduras onrradas]; éstos esse día estavan mezclados e envueltos con los cavalleros. (Traducción de las Décadas de Tito Livio, s. $\mathrm{XIV}$, CORDE).

La elipsis de la expresión los de la toga, que es recuperada en el miembro reformulado, omes vestidos de togas, es el mecanismo que opera en el establecimiento de la paráfrasis de (13). El segmento reformulado facilita así la comprensión del enunciado y resuelve la posible ambigüedad.

(14) Si sobre una demanda fueren muchos del una parte \& pocos o muchos dela otra, los alcalldes manden que cada una delas partes de quien razonen por si, $c a$ non deuen todos razonar, mas aquellos que fueren dados de amas las partes lo razonen, por que el pleyto non sse destorue por bozes njn por bueltas. (Fuero de Soria, s. XII, CORDE).

47 Pariente: se dice de todos los ascendientes, descendientes y colaterales de una familia, por consanguinidad o afinidad. Viene del Latino Parens. (Diccionario de Autoridades, 1737).

48 Aconpañados, de compaña: Comitiva y número de personas que lleva uno consigo o le acompañan, y van juntos en compañía. Comitiva: Acompañamiento, séquito de personas que lleva uno consigo, o que le acompañan, ahora sean criados y familiares suyos, o allegados que le siguen y cortejan. (Diccionario de Autoridades, 1729). 
La equivalencia semántica se produce por la antonimia parcial, mediante negación, que existe entre las expresiones cada una de las partes y non todos, en cuanto que la primera significa 'por separado' y la segunda se interpreta como 'no todos juntos'. La negación del segmento cada una de las partes: "no cada una de las partes", incluye, por una parte, 'todos', que niega el sema distributivo, y por otra parte, 'ninguno', en la que se niegan el sema distributivo y el sema cuantitativo. A su vez, 'ninguno' es 'no todos', donde caben 'algunos' y ${ }^{49}$ 'ninguno'. Y 'algunos' es precisamente el equivalente de 'no todos', puesto que este es su significado en el texto.

(15) [...] a él no se le olvida jamás una infinidad de exquisitas salsas y guisados excelentes, que se presentan en las mesas de los grandes Señores: conoce las casas de toda la corte donde se gasta más orden, más aseo, más opulencia en la mesa; que es decir, donde la gula hace más ostentación de su delicadeza. (Descripción del parásito, s. XVIII, CORDE).

La ironía, acompañada de la connotación y el paralelismo sintáctico, es el mecanismo responsable de la paráfrasis de (15). Considerando la gula como todo lo contrario de la delicadeza en la mesa, y dadas sus connotaciones de grosería y exageración, esta no puede hacer ostentación de su delicadeza. La gula, según el Diccionario de la Real Academia Española (1791), es 'el apetito desordenado de comer y beber, excediendo en el modo, en la calidad y en la cantidad'. Podríamos establecer, además, un paralelismo por correlatio entre estos tres elementos, modo, calidad y cantidad, y los respectivos que aparecen en el texto: orden, aseo y opulencia.

La metonimia resulta ser el mecanismo semántico más utilizado para el establecimiento de la relación de reformulación parafrástica, tanto en los textos literarios, como en los textos no literarios. Se observa, sin embargo, alguna diferencia en cuanto al orden de frecuencia en el que se dan los diferentes mecanismos parafrásticos empleados en los distintos tipos de textos. Así, en los textos literarios, la metáfora se sitúa por debajo de la metonimia, y después de la metáfora, la sinécdoque es el proceso más empleado. En los ejemplos tomados de textos no literarios, la anáfora conceptual se sitúa por debajo de la metonimia, encontrándose la metáfora por debajo de estos dos mecanismos, junto con la quasisinonimia y la ironía.

\begin{tabular}{|l|l|l|}
\hline Orden de prelación & TEXTOS LITERARIOS & TEXTOS NO LITERARIOS \\
\hline $\mathbf{1}^{\mathbf{0}}$ & metonimia & metonimia \\
\hline $\mathbf{2}^{\mathbf{o}}$ & metáfora & anáfora conceptual \\
\hline $\mathbf{3}^{\mathbf{0}}$ & sinécdoque & $\begin{array}{l}\text { metáfora } \\
\text { quasisinonimia } \\
\text { ironía }\end{array}$ \\
\hline
\end{tabular}

De manera general, los mecanismos semánticos menos utilizados son, en ambos tipos de textos, literarios y no literarios, la hipérbole, la antonomasia, la sinonimia y la hiperonimiahiponimia. En la relación parafrástica de los ejemplos de los textos literarios, la anáfora conceptual y la ironía son los mecanismos menos frecuentes, mientras que en los ejemplos tomados de textos no literarios, los mecanismos menos empleados son la hipérbole, la antonomasia y la polisemia.

49 Donde se da un significado colectivo ('algunos`y 'ninguno') y no una neutralización de significados ('algunos`o 'ninguno'). 
El contexto, tanto lingüístico como extralingüístico, cumple una función importante en el conjunto de los ejemplos analizados. Equivalencia contextual y equivalencia semántica se complementan en el establecimiento de la reformulación parafrástica. Sin embargo, la equivalencia puede ser únicamente pragmática en algunos casos, como se observa en (8), citado más arriba, donde el marcador reformulador parafrástico soporta todo el peso de la reformulación, y donde la equivalencia se establece por medio de un proceso inferencial apoyado en las connotaciones y asociaciones socio-culturales del término que se reformula. En otros casos, la equivalencia contextual puede adquirir un papel destacado para el establecimiento de la paráfrasis, si bien esta opera principalmente por medio de los mecanismos semánticos:

(16) E como ella supiesse que hauia de morir \& los borreros que la hauian de matar se allegassen, ella se adelanto a ellos sin temor alguno: muy luzida $\&$ vestida ricamente con sus damas $\&$ donzellas: \& no la oyeron llorar ni gemir: ante con gran coraçon \& animosamente: \& con gran esfuerço offrecio su cuerpo al cuchillo de sus enemigos: como si touiesse la muerte por cosa muy liuiana: que alos mas esforçados \& valientes caualleros suele ser abhorrecible. (De las mujeres ilustres en romance, $\mathrm{s} . \mathrm{XV}$, DAVIES).

La relación de equivalencia que se observa entre los segmentos con gran esfuerço offrecio su cuerpo al cuchillo de sus enemigos y touiesse la muerte por cosa muy liuiana, viene expresada principalmente mediante una metonimia basada en la contigüidad de instrumento por causa-efecto: el cuchillo-la muerte. Sin embargo, el contexto tiene un papel destacable que complementa la equivalencia entre ambos segmentos, ya que de él se deriva un proceso inferencial por el que se entiende el hecho de "ofrecer la mujer su cuerpo a la muerte con gran valor y valentía", como una acción de desprecio a la muerte, que hace que esta se considere "cosa muy liviana". Por medio de este proceso inferencial, se observa una relación causal entre los miembros de la reformulación. El autor del texto, considerando la osadía de la mujer y tomando como término de la comparación el hecho de que 'a los más esforzados y valientes caballeros suele ser aborrecible`, mediante la paráfrasis logra expresar al mismo tiempo su valoración en el segmento reformulado: 'la mujer tiene la muerte por cosa muy liviana`.

(17) Con los bombardeos, la ciudad se había transformado como se transforma una habitación cuando en ella muere su dueño. La ciudad se había enlutado; es decir, vivía obligadamente a oscuras. Prohibidas las luces después de la última acrobacia del sol, sin exceptuar las lámparas de mano. Todos los postigos se cerraban herméticamente y apenas si se veían resquicios aquí y allá. La ciudad a oscuras era impresionante y añadía misterio al ya misterioso hecho de ver y de morir y de matar. (Un millón de muertos, s. XX, CORDE).

La metonimia del tipo causa-efecto por la que opera la paráfrasis de (17), donde a su vez el efecto de enlutarse la ciudad metafóricamente es el de vivir obligadamente a oscuras, viene acompañada de otros mecanismos, como la connotación y la polisemia. También aquí el contexto es muy revelador, ya que en él se alude a los bombardeos, las muertes, el misterio, la falta de luz, permitiendo, así, la formación de los diferentes sentidos y connotaciones de los términos que constituyen el objeto de la reformulación y enriqueciendo semánticamente la comprensión e interpretación de la paráfrasis. 


\subsection{Mecanismos semánticos de resultado}

Dentro del corpus analizado para la presente investigación, la precisión se configura como el mecanismo de resultado que sobresale, con diferencia, respecto de otros mecanismos, tanto en los textos literarios, como en los no literarios. De aquí se deduce que la paráfrasis es empleada por el emisor fundamentalmente como un proceso de intensión semántica, para restringir el significado de lo que ha sido expresado en el segmento de referencia y hacerlo más específico.

El estudio nos ha permitido obtener diversos esquemas parafrásticos que no constan en la clasificación inicial tomada como punto de partida para el análisis del corpus seleccionado. Así, hemos considerado el esquema de la argumentación como un nuevo mecanismo de resultado del proceso parafrástico, como se puede observar en (16), donde el resultado de la paráfrasis se configura como una explicación que sirve de conclusión valorativa para justificar lo dicho en el segmento de referencia, y que se obtiene principalmente por medio de la equivalencia contextual entre los miembros de la reformulación. Asimismo, la argumentación se presenta en todos aquellos ejemplos cuya equivalencia viene acompañada por una relación de causa-efecto entre los segmentos discursivos, complementando así la función principal para la que se haya empleado la reformulación parafrástica. Por otra parte, cuando la paráfrasis opera por reducción o condensación del texto fuente, dentro del esquema general de la denominación, hemos incluido, como variante, el de la denominación metafórica, que hemos observado en los ejemplos tomados de los textos literarios. Veamos un ejemplo:

(18) E echauasse en oraçion \& llorando le pedia merçet quele troxiese çedo su señor en que metiera su corasçon \& ssu amor. El enperador ando tanto en ssus Romerias por muchas tierras estrañas fasta que fue detornada \& llego a tierra de Roma. Quando lo sopo la enperatris su spiritu torno en su corasçon como si Resuçitase. (De una santa emperatriz que hubo en Roma, s. XIV, DAVIES).

El modelo resultante del proceso parafrástico establecido entre tornar el espíritu a su corazón y resucitar se puede definir como una denominación metafórica, ya que "resucitar" se interpreta en su sentido traslaticio de 'renovar' o 'recobrar el ánimo' tras una situación lastimosa. El enunciado ha de ser entendido en su sentido no literal, por medio de un proceso metafórico-metonímico en el que la "vuelta a la vida" -que por metonimia se deduce a partir de la expresión su spiritu torno en su corasçon-, se identifica con la recuperación del ánimo. La analogía es facilitada por la polisemia del lexema "espíritu" y sus valores connotativos, considerando el espíritu como el motor que vivifica y proporciona fuerzas para la acción.

En el marco del esquema general de la definición, en los casos en los que la paráfrasis opera por expansión o desarrollo, hemos incluido un nuevo modelo parafrástico, al que hemos llamado definición contextual, y que se definiría como aquel que se configura como el resultado de la reformulación parafrástica basada únicamente en el contexto, la connotación y los valores implícitos de la expresión que se reformula, constituyéndose así en una equivalencia pragmática o contextual. Así se comprueba en (8), citado más arriba.

En cuanto al esquema de la precisión, se deriva de los resultados del corpus una subclasificación en: a) aclaración, cuando la precisión resuelve una ambigüedad previa; b) concreción, cuando la precisión reduce a lo esencial el significado de lo dicho en el segmento anterior; y c) matización, que sería el tipo de precisión que ofrece un plus semántico de información para decorar o puntualizar lo dicho, que ya estaba suficientemente claro. En el caso de la aclaración, esta se presenta en los casos analizados como el resultado de los mecanismos semánticos de la polisemia, la elipsis o la ironía: 
(19) La barba luenga e los cabellos avían desfigurado la hermosura del su rostro, mas todavía, maguer estava así desfigurado, falló quien lo conosciese; e dixeron que lo vieron qu'él sabía traer las órdenes (que quiere dezir, qu'él solía ser capitán de gentes d'armas), así que públicamente, aviendo piadat d'él, fue loado de muchos de grandes fechos que él fiziera de cavallería. (Traducción de las Décadas de Tito Livio, s. XIV, CORDE).

Como se observa en (19), la polisemia del término "órdenes" podría dar lugar a la ambigüedad, de modo que el enunciado podría no ser comprensible sin la paráfrasis. Esta ambigüedad se resuelve en el miembro reformulado mediante el enunciado metonímico solía ser capitán de gentes d'armas, que aclara que se trata de que 'sabía manejar las Órdenes de Caballería o las Órdenes Militares'.

En el caso de la concreción, se configura como el resultado del mecanismo de la metonimia en aquellos casos en los que lo abstracto se toma por lo concreto:

(20) Las simpatías naturales de la vieja reparadora y la niña reparada, se inclinaron por de pronto, como era de esperar, hacia el ingenioso químico que cobijaba en el rincón, y el cual no se hizo mucho de rogar para prestar a entrambas el apoyo de su espíritu, y colocar su laboratorio bajo la tutela y protección de ambas deidades. Aquí tenemos ya un triángulo no menos romántico que el de los dramas modernos, es a saber: -la gracia, la experiencia y la ciencia- o en otros términos -una muchacha, una vieja, y un doctor-. (Escenas y tipos matritenses, s. XIX, DAVIES).

El resultado de la relación parafrástica que existe entre los enunciados la gracia, la experiencia y la ciencia y una muchacha, una vieja y un doctor, viene a ser, como se deduce de la metonimia, una concreción de lo expresado en el segmento de referencia. Se observa una concreción gradual, que va desde lo más abstracto y general, en el enunciado la gracia, la experiencia y la ciencia, a conceptos menos abstractos y más definidos, por medio de la metonimia implícita ('la juventud, la vejez y la sabiduría'), para desembocar, en el segmento reformulado, en clases concretas de entidades, que pueden ser ya designables: una muchacha, una vieja y un doctor; para concluir finalmente en la referencia concreta o los denotata, que no se cita textualmente, pero que el lector infiere del contexto.

Por último, en el caso de la matización, se presenta como un tipo de precisión cuando en la paráfrasis han participado la connotación y la ironía:

(21) Por acá no se habla del tema. No sé qué malas artes emplea el coma-andante Castro para que en España no se le dé apenas aire a las noticias que lo vinculan con el terrorismo y el espionaje internacional. No sé por qué será, pero la tendencia general es la de pasar de puntillas por el tema, o lo que es lo mismo, correr un estúpido velo sobre las actividades extraterritoriales del coma y, como es lógico, una se siente más sola que un enano dando voces en el desierto. (La Razón, s. $\mathrm{XXI}$, CREA).

El resultado de los mecanismos semánticos por los que opera la paráfrasis en (21) es la extensión semántica del segmento que se reformula -una locución verbal manipulada: correr un tupido velo-, precisando su significado, pero también matizando el contenido por medio de la ironía, las connotaciones y valoraciones implícitas en el texto: 'tupido velo` > 'estúpido velo'.

El modelo general de la precisión, en sus diferentes variantes, se constituye como el esquema parafrástico más empleado, tanto en los textos literarios, como en los no literarios. Los demás mecanismos de resultado encontrados en el corpus: recapitulación parafrástica, resumen, generalización parafrástica, definición, definición contextual, denominación 
metafórica y argumentación, se muestran en general poco frecuentes y aparecen distribuidos por todas las épocas del español. Sin embargo, existen algunas diferencias, en orden de frecuencia, en el empleo de estos mecanismos en función del tipo de texto, y que quedan recogidas en el siguiente cuadro:

\begin{tabular}{|l|l|l|}
\hline Orden de prelación & TEXTOS LITERARIOS & TEXTOS NO LITERARIOS \\
\hline $\mathbf{1}^{\mathbf{0}}$ & precisión & precisión \\
\hline $\mathbf{2}^{\mathbf{0}}$ & $\begin{array}{l}\text { definición } \\
\text { denominación metafórica }\end{array}$ & recapitulación parafrástica \\
\hline $\mathbf{3}^{\mathbf{0}}$ & $\begin{array}{l}\text { recapitulación parafrástica } \\
\text { argumentación } \\
\text { resumen }\end{array}$ & generalización parafrástica \\
\hline
\end{tabular}

El esquema de la recapitulación parafrástica se da en los dos tipos de textos, si bien es más frecuente en los textos no literarios, mientras que en los textos literarios es de los mecanismos menos frecuentes, empleándose con la misma frecuencia que la argumentación y el resumen. Asimismo, la generalización parafrástica es un esquema que hemos hallado únicamente en ejemplos tomados de textos no literarios:

(22) La adversidad es la maestra más elocuente de individuos y sociedades, o en otros términos, el dolor espiritualiza al hombre, en tanto que la prosperidad le ata con más fuertes lazos al mundo sensible, a los goces animales. (El Bandolerismo. Estudio social y memorias históricas, s. XIX, CORDE).

La equivalencia se establece en (22) mediante diversos mecanismos: a) quasisinonimia, entre adversidad y dolor, si bien en la relación causa-efecto, el dolor puede tener muchas causas, entre ellas la adversidad; b) metonimia, en la que se toma lo concreto (la maestra) por lo abstracto (espiritualizar); y c) hiperonimia, al emplear el término más general, hombre, usado aquí con el sentido epiceno de 'ser humano', para abarcar los términos, de significado más particular, individuos y sociedades. El resultado de esta triple equivalencia es una generalización de lo expresado en el segmento de referencia, que es reformulado como una afirmación con carácter universal, casi con el valor de máxima.

La generalización parafrástica se presenta también en los casos en los que la equivalencia semántico-discursiva se establece por medio de la metonimia (símbolo-simbolizado) y por medio de la sinécdoque (parte-todo):

(23) Alemania no podía dejar caer el franco porque eso significaría atrasar la fecha establecida para la moneda única, o, lo que es lo mismo, un nuevo fracaso del proceso de unidad europea. Por esa razón, el Bundesbank no ha tenido más remedio que bajar los "repos". (El Mundo, s. XX, CORDE).

La sinécdoque del todo (el proceso de unidad europea) que se toma por la parte (la moneda única) se constituiría también como una metonimia en la que lo simbolizado (la unidad europea) se toma por el símbolo (la moneda única), teniendo en cuenta el contexto extralingüístico, mediante el cual se conoce que el proyecto de unión de todos los países europeos tiene su pilar fundamental en el establecimiento de la moneda única.

Igualmente hemos observado que en el caso de la recapitulación parafrástica, esta se configura como resultado de la paráfrasis en los casos en los que la anáfora conceptual resulta 
ser el mecanismo semántico principal por el que se establece la equivalencia semánticodiscursiva:

(24) [...] "o una conquista, o una revolución", que empieza a latir en la opinión de nuestro país y que no ha carecido de intérpretes en esta Información. Ahora bien, esa revolución súbita supone como necesaria condición estas tres cosas a la vez: genio político que la promueva y dirija; una organización vieja que no la estorbe; un estado social que la pueda asimilar. $O$ dicho de otro modo: hace falta poco menos que un milagro. (Oligarquía y caciquismo como la forma actual de gobierno en España: memoria y resumen de la información, s. XIX, DAVIES).

En (24), el término milagro es el anáforo que recoge los tres enunciados yuxtapuestos que constituyen el segmento de referencia: 1) genio político que la promueva y dirija; 2) una organización vieja que no la estorbe; y 3) un estado social que la pueda asimilar. Mediante la ironía y la hipérbole implicados en el significado de 'milagro`, la anáfora conceptual enriquece y valora semánticamente los enunciados que se reformulan. El contexto extralingüístico (situación y condiciones político-sociales de España), de nuevo, resulta fundamental para comprender la ironía del enunciado.

\section{Síntesis: esquematización de los modelos parafrásticos ${ }^{50}$}

\section{A) Textos literarios}

\begin{tabular}{|c|c|c|c|}
\hline & $\begin{array}{l}\text { Marcador } \\
\text { reformulador }\end{array}$ & $\begin{array}{l}\text { Mecanismos } \\
\text { semánticos de proceso }\end{array}$ & $\begin{array}{l}\text { Mecanismos semánticos } \\
\text { de resultado }\end{array}$ \\
\hline \multirow{2}{*}{ SIGLO XII } & $\begin{array}{l}\text { (1) } \\
\text { commo si }\end{array}$ & anáfora conceptual & recapitulación parafrástica \\
\hline & $\begin{array}{l}(2) \\
c a\end{array}$ & sinécdoque (parte-todo) & precisión \\
\hline \multirow[t]{2}{*}{ SIGLO XIII } & $\begin{array}{l}\text { (3) } \\
\text { que quiere dezir }\end{array}$ & $\begin{array}{l}\text { 3.1. antonimia } \\
\text { antonomasia } \\
\text { sinonimia } \\
\text { 3.2. hiperonimia } \\
\text { sinonimia }\end{array}$ & $\begin{array}{l}\text { 3.1. definición } \\
\text { 3.2. precisión }\end{array}$ \\
\hline & $\begin{array}{l}\text { (4) } \\
\text { esto es }\end{array}$ & $\begin{array}{l}\text { metonimia (continente- } \\
\text { contenido) }\end{array}$ & precisión \\
\hline SIGLO XIV & $\begin{array}{l}\text { (5) } \\
\text { como si }\end{array}$ & $\begin{array}{l}\text { hipérbole } \\
\text { metáfora } \\
\text { metonimia } \quad \text { (causa- } \\
\text { efecto) } \\
\text { metonimia implícita } \\
\text { (causa-efecto) }\end{array}$ & precisión \\
\hline
\end{tabular}

50 Los números entre paréntesis que aparecen en las tablas corresponden al número de cada uno de los cuarenta ejemplos parafrásticos que han sido analizados en toda esta investigación. Si las tablas los recogen en su totalidad, el artículo solo ha tenido en cuenta una selección de ejemplos para comentarlos ( 24 ejemplos en el cuerpo del texto y 10 ejemplos en las notas a pie de página). 


\begin{tabular}{|c|c|c|c|}
\hline & $\begin{array}{l}\text { (6) } \\
\text { como si }\end{array}$ & $\begin{array}{l}\text { antonimia implícita } \\
\text { connotación } \\
\text { metáfora } \\
\text { metonimia } \quad \text { (efecto- } \\
\text { causa) } \\
\text { metonimia } \quad \text { (causa- } \\
\text { efecto) } \\
\text { metonimia (símbolo- } \\
\text { simbolizado) } \\
\text { polisemia }\end{array}$ & denominación metafórica \\
\hline \multirow[t]{2}{*}{ SIGLO XV } & $\begin{array}{l}(7) \\
\text { como si }\end{array}$ & $\begin{array}{l}\text { contexto } \\
\text { metonimia } \\
\text { (instrumento-efecto) } \\
\text { metonimia (causa- } \\
\text { efecto) }\end{array}$ & $\begin{array}{l}\text { argumentación } \\
\text { (explicación más } \\
\text { conclusión valorativa) }\end{array}$ \\
\hline & $\begin{array}{l}\text { (8) } \\
\text { como si }\end{array}$ & $\begin{array}{l}\text { b) metáfora } \\
\text { sinonimia } \\
\text { c) quasisinonimia }\end{array}$ & $\begin{array}{l}\text { b) precisión } \\
\text { c) resumen }\end{array}$ \\
\hline \multirow{2}{*}{ SIGLO XVI } & $\begin{array}{l}\text { (9) } \\
\text { esto es }\end{array}$ & $\begin{array}{l}\text { hiperonimia } \\
\text { metáfora metonímica }\end{array}$ & precisión \\
\hline & $\begin{array}{l}\text { (10) } \\
\text { esto es }\end{array}$ & metáfora & $\begin{array}{l}\text { precisión (explicación de } \\
\text { la metáfora) }\end{array}$ \\
\hline \multirow[t]{2}{*}{ SIGLO XVII } & $\begin{array}{l}(11) \\
\text { como si }\end{array}$ & $\begin{array}{l}\text { connotación } \\
\text { metáfora (in praesentia) } \\
\text { metonimia (causa- } \\
\text { efecto) }\end{array}$ & $\begin{array}{ll}\text { variante } & \text { estilística } \\
\text { (intención } & \text { estilística, } \\
\text { énfasis) } & \end{array}$ \\
\hline & $\begin{array}{l}(12) \\
\text { esto es }\end{array}$ & metáfora & $\begin{array}{l}\text { variante de } \\
\text { (traducción } \\
\text { metáfora) }\end{array}$ \\
\hline \multirow[t]{2}{*}{ SIGLO XVIII } & $\begin{array}{l}\text { (13) } \\
\text { esto es }\end{array}$ & $\begin{array}{ll}\text { polisemia } & \\
\text { sinécdoque } & \text { (todo- } \\
\text { partes) } & \\
\text { sinécdoque } & \text { (plural- } \\
\text { singular) } & \end{array}$ & $\begin{array}{l}\text { precisión/aclaración } \\
\text { (resuelve ambigüedad) }\end{array}$ \\
\hline & $\begin{array}{l}\text { (14) } \\
\text { esto es }\end{array}$ & metáfora & $\begin{array}{l}\text { denominación metafórica } \\
\text { más precisión }\end{array}$ \\
\hline \multirow[t]{2}{*}{ SIGLO XIX } & $\begin{array}{l}(15) \\
\text { en otros términos }\end{array}$ & $\begin{array}{l}\text { metonimia (concreto- } \\
\text { abstracto) } \\
\text { metonimia implícita } \\
\text { (concreto-abstracto) }\end{array}$ & precisión/concreción \\
\hline & $\begin{array}{l}\text { (16) } \\
\text { lo que es igual }\end{array}$ & $\begin{array}{l}\text { hipérbole } \\
\text { ironía } \\
\text { sinécdoque (parte-todo) }\end{array}$ & $\begin{array}{l}\text { precisión } \\
\text { argumentación }\end{array}$ \\
\hline SIGLO XX & $\begin{array}{l}(17) \\
\text { es decir }\end{array}$ & $\begin{array}{l}\text { connotación } \\
\text { contexto } \\
\text { metáfora } \\
\text { metonimia (efecto- } \\
\text { causa) } \\
\text { metonimia (lugar- } \\
\text { habitante del lugar) } \\
\text { polisemia }\end{array}$ & precisión \\
\hline
\end{tabular}




\begin{tabular}{|l|l|l|l|}
\hline & $\begin{array}{l}(18) \\
\text { es decir }\end{array}$ & $\begin{array}{l}\text { connotación } \\
\text { contexto }\end{array}$ & $\begin{array}{l}\text { definición contextual más } \\
\text { argumentación }\end{array}$ \\
\hline \multirow{3}{*}{ SIGLO XXI } & $\begin{array}{l}\text { metáfora } \\
\text { como si }\end{array}$ & $\begin{array}{l}\text { antonimia } \\
\text { antonomasia } \\
\text { connotación } \\
\text { contexto } \\
\text { metonimia (acción- } \\
\text { resultado) } \\
\text { sinécdoque (todo-parte) }\end{array}$ & precisión \\
\hline & como si &
\end{tabular}

\section{B) Textos no literarios}

\begin{tabular}{|c|c|c|c|}
\hline & $\begin{array}{l}\text { Marcador } \\
\text { reformulador }\end{array}$ & $\begin{array}{l}\text { Mecanismos } \\
\text { semánticos de proceso }\end{array}$ & $\begin{array}{l}\text { Mecanismos } \\
\text { semánticos } \\
\text { resultado }\end{array}$ \\
\hline \multirow{2}{*}{ SIGLO XII } & $\begin{array}{l}(21) \\
\text { esto es }\end{array}$ & metáfora metonímica & $\begin{array}{l}\text { precisión/aclaración } \\
\text { (resuelve la } \\
\text { ambigüedad) }\end{array}$ \\
\hline & $\begin{array}{l}(22) \\
c a\end{array}$ & oposición (antítesis) & precisión \\
\hline \multirow[b]{2}{*}{ SIGLO XIII } & $\begin{array}{l}\text { (23) } \\
\text { a) que quiere tanto } \\
\text { dezir como } \\
\text { c) ca }\end{array}$ & $\begin{array}{l}\text { a) sinonimia } \\
\text { c) metáfora }\end{array}$ & $\begin{array}{l}\text { a) variante de traducción } \\
\text { intralingüística } \\
\text { c) precisión }\end{array}$ \\
\hline & $\begin{array}{l}\text { (24) } \\
\text { esto es }\end{array}$ & $\begin{array}{l}\text { antonomasia } \\
\text { hiperonimia-hiponimia } \\
\text { metonimia } \\
\text { (instrumento-el que lo } \\
\text { utiliza) } \\
\text { polisemia } \\
\text { quasisinonimia }\end{array}$ & precisión \\
\hline \multirow{2}{*}{ SIGLO XIV } & $\begin{array}{l}\text { (25) } \\
\text { que quiere dezir }\end{array}$ & elipsis & $\begin{array}{l}\text { precisión/aclaración } \\
\text { (resuelve la } \\
\text { ambigüedad) }\end{array}$ \\
\hline & $\begin{array}{l}\text { (26) } \\
\text { que quiere dezir }\end{array}$ & $\begin{array}{l}\text { metonimia (estamento- } \\
\text { el que lo constituye) } \\
\text { polisemia }\end{array}$ & $\begin{array}{l}\text { precisión/aclaración } \\
\text { (resuelve la } \\
\text { ambigüedad) }\end{array}$ \\
\hline \multirow{2}{*}{ SIGLO XV } & $\begin{array}{l}\text { (27) } \\
\text { que quiere tanto dezir } \\
\text { commo }\end{array}$ & anáfora conceptual & $\begin{array}{l}\text { recapitulación } \\
\text { parafrástica }\end{array}$ \\
\hline & $\begin{array}{l}\text { (28) } \\
\text { bien así como si }\end{array}$ & sinécdoque (parte-todo) & precisión más énfasis \\
\hline SIGLO XVI & $\begin{array}{l}\text { (29) } \\
\text { que quiere dezir }\end{array}$ & $\begin{array}{l}\text { denotación } \\
\text { metonimia (concreto- }\end{array}$ & $\begin{array}{l}\text { precisión más } \\
\text { concreción }\end{array}$ \\
\hline
\end{tabular}




\begin{tabular}{|c|c|c|c|}
\hline & & quasisinonimia & \\
\hline & $\begin{array}{l}\text { (30) } \\
\text { es a saber }\end{array}$ & $\begin{array}{l}\text { hiperonimia-hiponimia } \\
\text { metonimia } \\
\text { abstracto) } \\
\text { sinécdoque } \\
\text { singular) }\end{array}$ & $\begin{array}{l}\text { precisión } \\
\text { concreción }\end{array}$ \\
\hline & $\begin{array}{l}\text { (31) } \\
\text { lo que es lo mismo }\end{array}$ & $\begin{array}{l}\text { metonimia } \\
\text { (materia/objeto-lugar) } \\
\text { metonimia (efecto- } \\
\text { causa) }\end{array}$ & precisión \\
\hline SIGLO XVII & $\begin{array}{l}\text { (32) } \\
\text { es a saber }\end{array}$ & $\begin{array}{l}\text { antonimia } \\
\text { metonimia } \\
\text { efecto) } \\
\text { metonimia (causa- } \\
\text { instrumento) }\end{array}$ & precisión \\
\hline & $\begin{array}{l}\text { (33) } \\
\text { en otros términos }\end{array}$ & $\begin{array}{l}\text { metonimia } \\
\text { efecto) }\end{array}$ & resumen más conclusión \\
\hline & $\begin{array}{l}\text { (34) } \\
\text { que es decir }\end{array}$ & $\begin{array}{l}\text { ironía } \\
\text { connotación }\end{array}$ & resumen más aclaración \\
\hline SIGLO XIX & $\begin{array}{l}\text { (35) } \\
\text { en otros términos }\end{array}$ & $\begin{array}{l}\text { antonimia } \\
\text { hiperonimia-hiponimia } \\
\text { metonimia (causa- } \\
\text { efecto) } \\
\text { metonimia (concreto- } \\
\text { abstracto) } \\
\text { quasisinonimia }\end{array}$ & generalización \\
\hline & $\begin{array}{l}(36) \\
\text { dicho de otro modo }\end{array}$ & $\begin{array}{l}\text { anáfora conceptual } \\
\text { hipérbole } \\
\text { ironía }\end{array}$ & $\begin{array}{l}\text { recapitulación } \\
\text { parafrástica }\end{array}$ \\
\hline CICI OYY & $\begin{array}{l}\text { (37) } \\
\text { lo que es lo mismo }\end{array}$ & $\begin{array}{l}\text { metonimia (símbolo- } \\
\text { simbolizado) } \\
\text { sinécdoque (todo-parte) }\end{array}$ & generalización \\
\hline SIGLU AA & $\begin{array}{l}(38) \\
\text { dicho en otras palabras }\end{array}$ & anáfora conceptual & $\begin{array}{l}\text { recapitulación } \\
\text { parafrástica }\end{array}$ \\
\hline SICI $O$ YYI & $\begin{array}{l}\text { (39) } \\
\text { lo que es lo mismo }\end{array}$ & $\begin{array}{l}\text { metáfora metonímica } \\
\text { (instrumento-el que lo } \\
\text { utiliza) } \\
\text { sinonimia }\end{array}$ & precisión \\
\hline SGLO XXI & $\begin{array}{l}\text { (40) } \\
\text { lo que es lo mismo }\end{array}$ & $\begin{array}{l}\text { anáfora conceptual } \\
\text { ironía } \\
\text { quasisinonimia } \\
\text { connotación }\end{array}$ & $\begin{array}{l}\text { precisión } \\
\text { matización }\end{array}$ \\
\hline
\end{tabular}


9.1. Evolución tipológica (A.1, A.2, A.3; B.1, B.2, B.3) y cronológica (siglos XII-XXI) de los esquemas parafrásticos analizados en el corpus de este trabajo

A) Textos literarios

A.1. Evolución de los marcadores reformuladores:

\begin{tabular}{|l|l|l|l|l|l|l|l|l|l|l|}
\hline siglos & XII & XIII & XIV & XV & XVI & XVII & XVIII & XIX & XX & XXI \\
\hline ca & + & & & & & & & & & \\
\hline como si & + & & + & + & & + & & & & + \\
\hline en otros términos & & & & & & & & + & & \\
\hline es decir & & & & & & & & & + & \\
\hline esto es & & + & & & + & + & + & & \\
\hline $\begin{array}{l}\text { lo que es igual } \\
\text { que quiere decir }\end{array}$ & & & & & & & & + & \\
\hline
\end{tabular}

A.2. Evolución de los mecanismos semánticos de proceso:

\begin{tabular}{|c|c|c|c|c|c|c|c|c|c|c|}
\hline siglos & XII & XIII & XIV & XV & XVI & XVII & XVIII & XIX & $\mathrm{XX}$ & XXI \\
\hline anáfora conceptual & + & & & & & & & & & \\
\hline antonimia & & + & + & & & & & & & + \\
\hline antonomasia & & + & & & & & & & & + \\
\hline connotación & & & + & & & + & & & + & + \\
\hline contexto & & & & + & & & & & + & + \\
\hline hipérbole & & & + & & & & & + & & \\
\hline $\begin{array}{l}\text { hiperonimia- } \\
\text { hiponimia }\end{array}$ & & + & & & + & & & & & \\
\hline ironía & & & & & & & & + & & \\
\hline metáfora & & & + & + & + & + & + & & + & + \\
\hline metonimia & & + & + & + & & + & & + & + & + \\
\hline polisemia & & & + & & & & + & & + & \\
\hline quasisinonimia & & & & + & & & & & & \\
\hline sinécdoque & + & & & & & & + & + & + & + \\
\hline sinonimia & & + & & & & & & & & \\
\hline
\end{tabular}


A.3. Evolución de los mecanismos semánticos de resultado:

\begin{tabular}{|c|c|c|c|c|c|c|c|c|c|c|}
\hline siglos & XII & XIII & XIV & XV & XVI & XVII & XVIII & XIX & XX & XXI \\
\hline argumentación & & & & + & & & & & & \\
\hline definición & & + & & & & & & & + & \\
\hline denominación & & & + & & & & + & & & \\
\hline precisión & + & + & + & + & + & & + & + & + & + \\
\hline recapitulación & + & & & & & & & & & \\
\hline resumen & & & & + & & & & & & \\
\hline variante & & & & & & + & & & & \\
\hline
\end{tabular}

B) Textos no literarios

B.1. Evolución de los marcadores reformuladores:

\begin{tabular}{|c|c|c|c|c|c|c|c|c|c|c|}
\hline siglos & XII & XIII & XIV & XV & XVI & XVII & XVIII & XIX & XX & $\mathbf{X X I}$ \\
\hline bien así como si & & & & + & & & & & & \\
\hline$c a$ & + & + & & & & & & & & \\
\hline dicho de otro modo & & & & & & & & + & & \\
\hline $\begin{array}{l}\text { dicho en otras } \\
\text { palabras }\end{array}$ & & & & & & & & & + & \\
\hline en otros términos & & & & & & & + & + & & \\
\hline es a saber & & & & & + & + & & & & \\
\hline esto es & + & + & & & & & & & & \\
\hline lo que es lo mismo & & & & & & + & & & + & + \\
\hline que es decir & & & & & & & + & & & \\
\hline que quiere decir & & & + & & + & & & & & \\
\hline $\begin{array}{l}\text { que quiere tanto } \\
\text { decir como }\end{array}$ & & + & & + & & & & & & \\
\hline
\end{tabular}

B.2. Evolución de los mecanismos semánticos de proceso:

\begin{tabular}{|l|l|l|l|l|l|l|l|l|l|l|}
\hline siglos & XII & XIII & XIV & XV & XVI & XVII & XVIII & XIX & XX & XXI \\
\hline $\begin{array}{l}\text { anáfora conceptual } \\
\text { antonimia }\end{array}$ & & & & + & & & & + & + & + \\
\hline $\begin{array}{l}\text { antonomasia } \\
\text { connotación }\end{array}$ & & + & & & & & & & & \\
\hline $\begin{array}{l}\text { denotación } \\
\text { elipsis } \\
\text { hipérbole }\end{array}$ & & & & & & & + & & & + \\
\hline
\end{tabular}




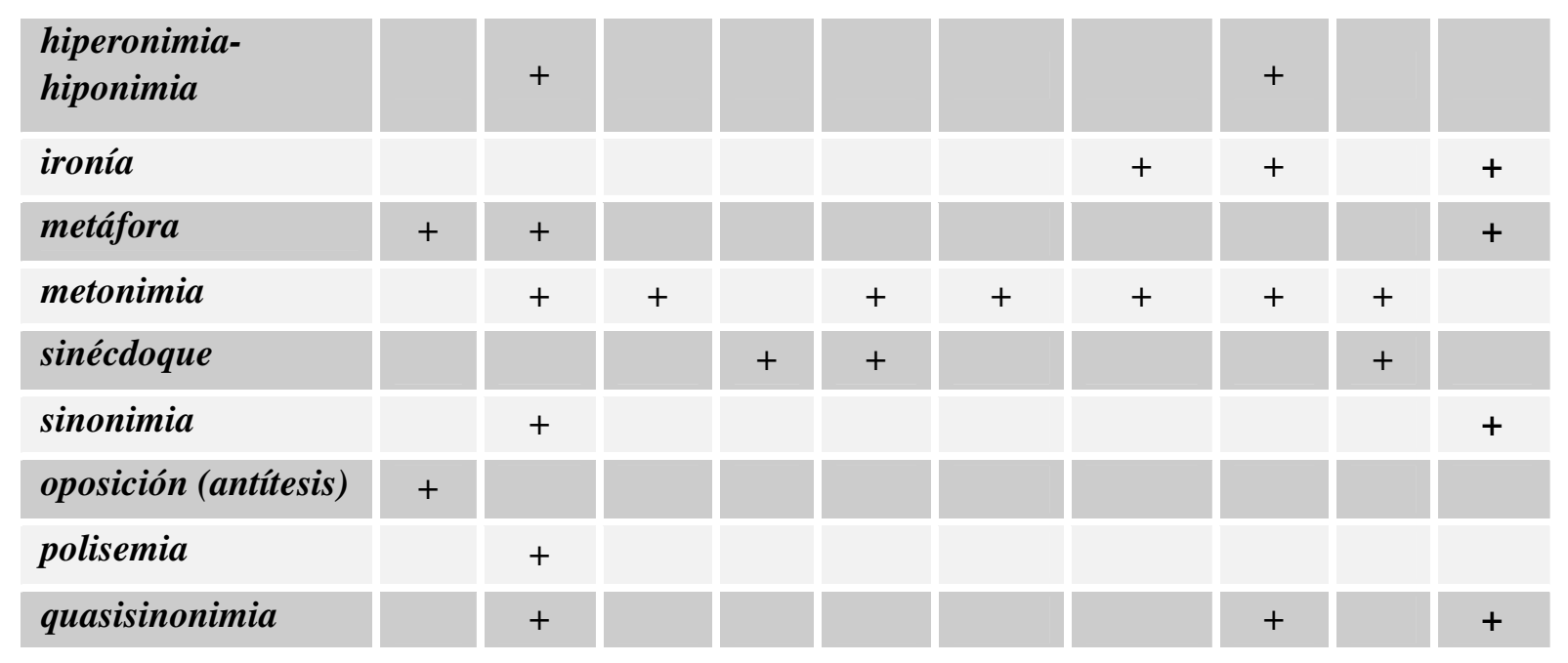

B.3. Evolución de los mecanismos semánticos de resultado:

\begin{tabular}{|c|c|c|c|c|c|c|c|c|c|c|}
\hline siglos & XII & XIII & XIV & XV & XVI & XVII & XVIII & XIX & XX & XXI \\
\hline generalización & & & & & & & & + & + & \\
\hline precisión & + & + & + & + & + & + & & & & + \\
\hline recapitulación & & & & + & & & & + & + & \\
\hline resumen & & & & & & & + & & & \\
\hline variante & & + & & & & & & & & \\
\hline
\end{tabular}

\section{Conclusión}

Son diversos los mecanismos semánticos por los cuales se puede establecer la equivalencia semántico-discursiva que caracteriza el proceso de la reformulación parafrástica: anáfora conceptual, antonimia, antonomasia, denotación, connotación, elipsis, hendíadis, hipérbole, hiperonimia-hiponimia, ironía, metáfora, metonimia, sinécdoque, sinonimia, quasisinonimia, antítesis, pleonasmo, polisemia y simbología. La paráfrasis puede operar, o bien mediante un conjunto de mecanismos o bien mediante un único mecanismo hegemónico, que soporta por sí solo la relación de equivalencia. En este último caso, son la anáfora conceptual, la metáfora, la metonimia y la sinécdoque los mecanismos que de manera más frecuente pueden aparecer en un enunciado parafrástico siendo los únicos responsables de la reformulación.

Hay determinados mecanismos que cumplen una función secundaria y se presentan siempre acompañando a otros, que tienen mayor relevancia en el establecimiento de la paráfrasis, y son la antonomasia, la hipérbole y la polisemia. Por lo tanto, se comprueba que en los casos en que la paráfrasis opera mediante la combinación de varios procesos semánticos, hay un determinado mecanismo que tiene un papel hegemónico en el establecimiento de la equivalencia y que es acompañado por otros mecanismos, que lo complementan de manera secundaria.

No se observan diferencias importantes en el funcionamiento de la paráfrasis en los textos literarios y en los no literarios; los diferentes tipos de metonimia se configuran, en ambos 
tipos de textos, como los mecanismos semánticos más empleados. Asimismo, los menos empleados son la hipérbole, la antonomasia, la sinonimia léxica y la hiperonimia-hiponimia.

La equivalencia basada en la mayor o menor identidad de las estructuras semánticas de los segmentos de la reformulación y la equivalencia basada fundamentalmente en los vínculos implícitos existentes entre las expresiones de la relación parafrástica, que se deduce de un proceso inferencial, no se dan de manera aislada, por separado, sino que en la mayoría de los casos aparecen unidas y se complementan. Equivalencia semántica y equivalencia pragmática se complementan en el proceso de la reformulación parafrástica, ya que el contexto, tanto textual como extralingüístico, constituye un apoyo, con mayor o menor relevancia según los casos, que complementa y refuerza la equivalencia semántica. Por esta razón se ha definido la paráfrasis como una relación de equivalencia semántico-pragmática.

La paráfrasis se emplea principalmente como un instrumento discursivo de intensión semántica para restringir el significado de lo que ha sido expresado en un enunciado anterior y hacerlo más específico. Tampoco aquí se producen diferencias relevantes en lo que respecta a la distinción entre textos literarios y textos no literarios. La precisión se configura, por tanto, como el resultado más frecuente del proceso de la reformulación parafrástica, si bien se pueden destacar diversos subtipos dentro de esta finalidad principal: aclaración, concreción y matización, cada uno de los cuales se presenta como el resultado de unos mecanismos semánticos determinados. Asimismo, la paráfrasis es empleada por el hablante con otros objetivos e intenciones, aunque menos frecuentes: la recapitulación parafrástica, el resumen, la generalización parafrástica, la definición, la definición contextual y la denominación metafórica. La argumentación se configura como resultado de la paráfrasis en determinados casos en los que esta supone una explicación que sirve de conclusión valorativa para justificar lo dicho en el segmento de referencia y en la que la equivalencia contextual cumple un papel sobresaliente. Sin embargo, parece más propio considerar la argumentación como complemento de los otros resultados de la paráfrasis y no como una finalidad en sí misma, ya que se encuentra frecuentemente acompañando a otros esquemas parafrásticos, como la precisión, la definición contextual y aquellos en los que se da una relación causal entre los enunciados de la reformulación.

Es importante señalar que en determinados esquemas parafrásticos, cuando la paráfrasis opera por medio de un conjunto de mecanismos semánticos, hay un mecanismo que se erige en el preponderante o hegemónico y es el que determina el resultado de la paráfrasis. Así, en el caso de la recapitulación parafrástica, se constata que la anáfora conceptual constituye el mecanismo principal; y en el caso de la generalización parafrástica, priman los mecanismos de la quasisinonimia y la hiperonimia-hiponimia, así como la metonimia (símbolosimbolizado; concreto-abstracto) y la sinécdoque (parte-todo). Asimismo, la aclaración, empleada para resolver una ambigüedad previa, se configura como el resultado de los mecanismos semánticos de la polisemia, la elipsis o la ironía; la concreción, en la que se reduce a lo esencial el significado de lo dicho, se presenta como resultado del tipo de metonimia en la que lo concreto se toma por lo abstracto; y la matización, que pretende detallar algo que se ha dicho y que ya estaba suficientemente claro, se da cuando en la paráfrasis han participado la connotación y la ironía. De aquí se concluye que de todos los mecanismos semánticos estudiados por los que puede operar la paráfrasis, no hay unos más importantes que otros, pero sí hay unos que se comportan como más propios de un determinado esquema o resultado parafrástico, y otros, como más propios para dar lugar a otros resultados parafrásticos determinados. 
Por último, resulta posible estructurar integralmente las manifestaciones de la reformulación de acuerdo con las dimensiones reales y funcionales del hablar. Siguiendo a E. Coseriu (1992) y sus tres niveles del hablar -el universal, el idiomático y el discursivo o individual-, la reformulación es fácilmente clasificable, como reformulación en el plano cognitivo (propiciado por la "designación"), en el plano de la lengua (en sus distintos niveles: léxico, sintáctico, transfrástico) y en el plano discursivo. Y aun en este último plano, en distintos subniveles: sobre todo, en el de la tradicionalidad del discurso y en el individual. Los ejemplos que se aducen pueden sintetizarlo:

1. Reformulación en el plano cognitivo, representacional o designativo: la blanca nieve = 'la nieve con su blancura'

2. Reformulación en el plano idiomático:

a) Léxico: relaciones semánticas de hiperonimia, sinonimia, parasinonimia, etc., por ejemplo:

$\left.\mathrm{a}_{1}\right)$ Que constituyen el desfallecimiento, lo que generalmente se dice encontrarse mal, donde la expresión encontrarse mal es el hiperónimo de desfallecer

b) Sintáctico:

$\mathrm{b}_{1}$ ) Este establecimiento vende panes (activa)

$\mathrm{b}_{2}$ ) En este establecimiento se venden panes (pasiva refleja)

$\mathrm{b}_{3}$ ) En este establecimiento se vende panes (impersonal)

c) Transfrástico: con los marcadores (o sea, es decir, esto es...), por ejemplo:

$\mathrm{c}_{1}$ ) Dada en Gaget. viii dias antes de las Kalendas de abril. Esto es; ocho días por andar del mes de março

3. Reformulación en el plano discursivo:

a) En el nivel de las tradiciones discursivas: los aspectos de norma y distribución recogidos en $\S 8.2$ y $\S 8.3$, para los textos literarios y no literarios.

b) En el plano individual: los ejemplos de encapsulación anafórica, por ejemplo:

$\mathrm{b}_{1}$ ) [...] derecho que ha de auer el obispo de los clerigos de su obispado que son estos: que deuen venir quando los llamaren a synodo: \& soterrar los muertos: \& fazer proçession leyendo el perlado en el lugar: \& en darle catredatico cada año que es dos sueldos de la moneda mas comunal que ay en la tierra: y la terçera y la quarta parte de las mandas que los onbres fazen a los clerigos a sus finamientos segund que es costumbre a cada lugar: \& otrosy en dar le la terçia o la quarta parte de los diezmos o procuraçion \& posada: que quiere tanto dezir commo darle la despensa ${ }^{51}$.

51 La anáfora conceptual tiene como segmento de referencia un enunciado compuesto de tres elementos: 1) dar le la terçia o la quarta parte de los diezmos; 2) [dar le] procuraçion; y 3) [dar le] posada, que están contenidos en el enunciado reformulado, que los abarca: darle la despensa, donde despensa es un sintagma nominal anafórico que recoge y etiqueta, enriqueciendo, los tres conceptos expresados en el enunciado anterior. 


\section{Bibliografía}

Alarcos, Emilio (1994): Gramática de la Lengua Española. Madrid: Espasa Calpe.

Arduini, Stefano (2000): Prolegómenos a una teoría general de las figuras. Murcia: Universidad de Murcia.

Bernabé, Alberto (ed.) (2007): Retórica de Aristóteles. Madrid: Alianza Editorial.

Bès, Gabriel G./ Fuchs, Catherine (coords.) (1988): Lexique et paraphrase. Lille: Presses Universitaires de Lille.

Bialystok, Ellen (1991): Language Processing in bilingual children: a model of language learning in social context. Cambridge: Cambridge University Press.

Coseriu, Eugenio (1977): Principios de semántica estructural. Madrid: Editorial Gredos.

Coseriu, Eugenio (1992): Competencia lingüística. Elementos de la teoría del hablar. Madrid: Editorial Gredos.

Crawley, Sharon J./ Mountain, Lee H. (1995): Strategies for guiding content reading. Boston: Allyn \& Bacon.

Derksen, Clarence F./ Frederiks, Paul J. M. (1996): "Paraphrasing as a technique to support object-oriented analysis"

(http://citeseerx.ist.psu.edu/viewdoc/summary?doi=10.1.1.54.2963).

Diccionario de la Real Academia de la Lengua Española. Diversas ediciones digitalizadas de Autoridades y DRAE.

(http://buscon.rae.es/ntlle/SrvltGUIMenuNtlle?cmd=Lema\&sec=1.0.0.0.0.).

Diccionario ilustrado VOX latino-español, español-latino. Barcelona: Biblograf, $20^{\mathrm{a}}$ ed. (reimpresión), 1996.

Fuchs, Catherine (1982): La paraphrase. Paris: Presses Universitaires de France.

Fuchs, Catherine (ed.) (1985): Aspects de l'ambigüité et de la paraphrase dans les langues naturelles. Berna: Peter Lang.

Fuchs, Catherine (1987): L'ambiguïté et la parapharase : operations linguistiques processus cognitifs traitements automatisés: Actes du colloque de Caen, 9-11 avril 1987 / publiés sous la direction de C. Fuchs avec le concurs du Centre National de la Recherche Scientifique. Caen: Université de Caen.

Fuchs, Catherine (1994): Paraphrase et énonciation. Paris: Ophrys.

Garcés, M ${ }^{\mathrm{a}}$ Pilar (2008): La organización del discurso: marcadores de ordenación y de reformulación. Madrid: Lingüística Iberoamericana.

Fernández, Marina/Anula, Alberto (1995): Sintaxis y cognición: introducción a la gramática generativa. Madrid: Síntesis.

García, Benjamín (1997a): "Sinonimia y diferencia de significado", en: Revista Española de Lingüística 27/1, 1-32.

García, Benjamín (1997b): "La sinonimia: relación onomasiológica en la antesala de la semántica”, en: Revista Española de Lingüística 27/2, 381-408.

Gleitman, Lila R./ Gleitman, Henry (1971): Phrase and paraphrase. Some innovative uses of language. New York: Norton.

González, Ramón (2009): "Algunas notas en torno a un mecanismo de cohesión textual: la anáfora conceptual”, en: Azucena Penas/González, Rosario (eds.): Estudios sobre el texto. Nuevos enfoques y propuestas. Frankfurt am Main: Peter Lang, 247-278.

Gutiérrez, Salvador (1989): Introducción a la semántica funcional. Madrid: Síntesis.

Harris, Zellig S. (1981): Papers on Syntax. London: D. Reidel Publishing Company. 
López, Ángel (1977): Elementos de semántica dinámica. Semántica española. Zaragoza: Pórtico.

Herrero, Francisco Javier (2009): "Cohesión lingüística en la Celestina: referencias al discurso mediante sustantivos de lengua", en: Azucena Penas/ González, Rosario (eds.): Estudios sobre el texto. Nuevos enfoques y propuestas. Frankfurt am Main: Peter Lang, 387-410.

Lumbelli, Lucia/Mortara, Bice (1999): Parafrasi: dalla teoría lingüística alla teoría psicopedagógica. Milano: Edizioni dell’Orso.

Lyons, John (1979): Semántica. Barcelona: Teide.

Martin, Robert (1976): Inférence, antonymie et paraphrase: éléments pour une théorie sémantique. Paris: Klincksieck.

Martín, Ma Antonia/Portolés, José (1999): "Los marcadores del discurso", en: Ignacio Bosque y Violeta Demonte (dirs.): Gramática Descriptiva de la Lengua Española. Madrid: Espasa, 4051-4213.

Martínez, Juan A. (1997): "Concreción y abstracción en el estudio de la sinonimia", en: Moenia 3, 157-169.

Nolan, Rita (1970): Foundations for an adequate criterion of paraphrase. The Hague-Paris: Mouton.

Nord, Christiane (2005): Text Analysis in Translation: Theory, Methodology and Didactic Application of a Model for Translation-oriented Text Analysis. Amsterdam: Rodopi.

Penas, Ma Azucena (2008a): "Sentido plural, connotación y polisemia", en: Analecta Malacitana 31/2, 441-473.

Penas, M ${ }^{\mathrm{a}}$ Azucena (2008b): "Paráfrasis por sinonimia, por hiperonimia y por antonimia" y "Sinonimia y su rendimiento en el texto y en la traducción". Dos Conferencias pronunciadas dentro del "Máster de Comunicación y Traducción". Universidad Hassan II de Casablanca, pertenecientes al Programa de Cooperación subvencionado por el Instituto Hispano-Luso de Rabat.

Penas, Ma Azucena (2008-2009a): "Fundamentos ontológicos de la metáfora como término semánticamente marcado con respecto al de ortonimia, metonimia, metáfora y peronimia dentro del eje onímico". Conferencia pronunciada en el marco de colaboración universitaria bilateral Erasmus-Sócrates dentro del programa de Doctorado, en el Dipartimento di Studi Europei Romazi de la Università degli Studi di Roma La Sapienza.

Penas, Ma Azucena (2008-2009b): "Sinonimia y paráfrasis", "La reformulación lingüística en el español como lengua extranjera" y "Sinonimia: aspectos teóricos fundamentales. Evolución de los estudios de la sinonimia en la historia". Conferencia pronunciada en el marco de colaboración universitaria bilateral Erasmus-Sócrates, dentro del programa de Doctorado, en el Departamento de Linguística de la Faculdade de Ciencias Sociais e Humanas de la Universidade Nova de Lisboa.

Penas, Ma Azucena (2009a): "El recorrido semántico del eje onímico en la traducción inter e intralingüística”, en: Azucena Penas/Martín, Raquel (eds. y coords.): Traducción e Interculturalidad. Aspectos metodológicos teóricos y prácticos. Rabat: Universidad Mohamed V de Rabat, Universidad de Bergen (Noruega) y Editorial CantArabia, 1-32.

Penas, Ma Azucena (2009b): "El principio sintáctico de linealidad en el hipotexto y el parámetro semántico-pragmático de continuidad en el hiper(ciber) texto", en: Azucena Penas/González, Rosario (eds.): Estudios sobre el texto. Nuevos enfoques y propuestas. Frankfurt am Main: Peter Lang, 115-158. 
Penas, M ${ }^{\mathrm{a}}$ Azucena (2009c): "Connotación e isotopía", en: Azucena Penas: Cambio semántico y competencia gramatical. Madrid-Frankfurt am Main: IberoamericanaVervuert, 77-109.

Penas, Ma Azucena y Milagros Alonso (2010): "Procesos inferenciales de semiotización en El Sur de Borges y Erice", en: Círculo de Lingüística Aplicada a la Comunicación 41, $107-$ 143.

Penas, $\mathbf{M}^{\mathrm{a}}$ Azucena (2011): "From Conceptual Meaning to Intentional Meaning in Argumentative Persuasion", en: Beatriz Penas et al. (eds.): Con/Texts of Persuasion. Kassel: Edition Reichenberger, 113-134.

Portolés, José (2001): Marcadores del discurso. Barcelona: Ariel.

Portolés, José (2004): Pragmática para hispanistas. Madrid: Síntesis.

Pottier, Bernard (1993): Semántica general. Madrid: Gredos.

Pottier, Bernard (2000): Représentations mentales et catégorisations linguistiques. LouvainParis: Éditions Peeters.

Prandi, Michele (1995): Gramática filosófica de los tropos. Madrid: Visor.

Rath, Rainer (1975): “Kommunikative Paraphrase”, en: Linguistik und Didaktik 22, 103-118.

Rath, Rainer (1979): Kommunikationspraxis. Analysen zur Textbildung und Textgliederung im gesprochenen Deutsch. Göttingen: Vandenhoeck \& Ruprecht.

Reyes, Graciela/Baena, Elisa/Urios, Eduardo (2005): Ejercicios de pragmática I. Madrid: Arco/Libros.

Sienra, Roberto (1995): La paráfrasis. Montevideo: Ediciones Cuerda.

Trujillo, Ramón (1996): Principios de semántica textual. Madrid: Arco/Libros.

Corpora empleados:

- Corpus Diacrónico del Español (CORDE)

(http://corpus.rae.es/cordenet.html)

- Corpus de Referencia del Español Actual (CREA)

(http://corpus.rae.es/creanet.html)

- Corpus de Davies

(http://corpusdelespanol.org/) 